\title{
Monetary Rules for Emerging Market Economies*
}

\author{
Fabio Ghironi ${ }^{\dagger} \quad$ Alessandro Rebucci ${ }^{\ddagger}$ \\ Boston College International Monetary Fund
}

First draft: October 9, 2000

This draft: August 13, 2001

Comments welcome

\begin{abstract}
We compare the performance of a currency board arrangement, inflation targeting, and dollarization in a small open, developing economy with liberalized capital account. We focus explicitly on the transmission of shocks to currency and country risk premia in international financial markets and on the role of fluctuations in premia in the propagation of other shocks. We calibrate our model on Argentina. The
\end{abstract}

${ }^{*}$ We thank Paul Bergin, Robert Flood, Francesco Giavazzi, Andrew Hughes-Hallett, Graciela Kaminsky, Andrew Levin, Fabrizio Perri, Andrew Powell, Carlo Sdralevich, Martín Uribe, and participants in the 2000 LACEA Conference, a SED session in the 2001 ASSA Meetings, the 2001 North American Summer Meeting of the Econometric Society, the 2001 SED Annual Meeting, and in seminars at NYU-Stern and the University of Pennsylvania for helpful comments. We are grateful to Eduardo Borensztein for sharing his data on risk premia with us and to Andrei Levchenko and Irina Telyukova for excellent research assistance. Remaining errors are ours. Work on this paper was undertaken also during visits by Ghironi to IGIER-Bocconi University and by Rebucci to Boston College. We thank these institutions for their hospitality. The views expressed in this paper are exclusively those of the authors and not those of the International Monetary Fund.

${ }^{\dagger}$ Department of Economics, Boston College, Carney Hall 131, Chestnut Hill, MA 02467-3806. E-mail: Fabio.Ghironi@bc.edu. URL: http://FMWWW.bc.edu/ECV/Ghironi.fac.html.

${ }_{\ddagger}^{\ddagger}$ Policy Development and Review Department, International Monetary Fund, 700 19th Street, NW, Washington, DC 20431. E-mail: ARebucci@imf.org. 
framework fits the data relatively well in that it matches the second moments of several key macro variables. Welfare analysis suggests that dollarization is preferable to the alternative regimes we consider because it removes the volatility that originates from the currency premium. However, a currency board can match dollarization if the central bank holds a sufficiently large stock of foreign reserves on average.

Keywords: Argentina; Business cycles; Emerging markets; Monetary rules; Risk premia; Welfare

JEL Classification: C52; E52; F41; O54

\section{Introduction}

The recent financial crises have reheated the debate on the relative merits of alternative monetary rules for emerging market economies. There is a consensus in favor of corner solutions such as pure floats with an inflation target as nominal anchor, currency board arrangements, or outright dollarization, and away from ordinary fixed exchange rate regimes and standard monetary anchors. However, the fundamental question of whether or not to retain an independent monetary policy in a small, open, developing economy with liberalized capital account remains open.

We compare the performance of a currency board arrangement, inflation targeting, and dollarization in emerging market economies. Our framework makes it possible to assess the consequences of different monetary rules both in terms of welfare and the dynamics of the main macro aggregates when the economy in question is subject to domestic and international exogenous disturbances. We focus on the transmission of shocks to risk premia in international financial markets as a major source of volatility for emerging markets. We distinguish explicitly between country risk and currency risk. The framework combines a theoretical model of business cycles in an open economy with an empirical model for the "rest-of-the-world" area and risk premia, which is estimated using Argentine and U.S. data. We evaluate the empirical performance of the apparatus by contrasting the second moments of Argentine data with those predicted by a reasonable calibration of the model. We then compare the quantitative predictions of the model for welfare under the alternative monetary rules considered.

Argentina has a currency board in place sine 1991 and is already a highly dollarized economy, though not officially. Proponents of dollarization argue 
that Argentina should move to full dollarization to reap the credibility benefits of locking the exchange rate irrevocably (Calvo, 2001; see also Mendoza, 2001, for a similar argument for Mexico). Proponents of inflation targeting, on the contrary, advocate a return to monetary policy independence, provided that adequate institutional arrangements are put in place (Mishkin, 2000). More generally, the tradeoff facing emerging markets in choosing between "corner solutions" is multi-dimensional. We abstract from institutional problems, including lender of last resort and seignorage issues. We do not model credibility theoretically. In our framework, the credibility of a regime is reflected in the estimated model of the risk premia. We focus on the regimes' comparative costs and benefits in terms of short-term business cycle dynamics and their implications for welfare.

We abstract also from balance-sheet effects and the financial accelerator channel. Devereux and Lane (2000) (henceforth, DL) explore the importance of the latter for monetary policy in an emerging market economy in the context of a microfounded model somewhat similar to ours. They find that the case for flexible exchange rates is weaker if constraints on external financing become more important. ${ }^{1}$ In our model, lags in the production-to-sale process provide an additional channel through which fluctuations in the cost of borrowing affect economic activity. The case for retaining the domestic currency is weaker if doing so causes more volatility in the cost of borrowing.

Cooley and Quadrini (2001) and Schmitt-Grohé and Uribe (2001) (henceforth, CQ and SGU, respectively) are other recent studies that compare monetary regimes for emerging market economies in microfounded models. ${ }^{2}$ SGU does not distinguish between default and currency risk; thus, a change in monetary regime has no impact on the external cost of borrowing. This might bias results against dollarization. The distinction between different premia is absent also in DL. This paper does not distinguish between foreign interest rate shocks (which we interpret as foreign monetary policy shocks) and shocks to the risk premium (which we attribute to the behavior of private investors in financial markets) either. There is no way to differentiate a standard fixed exchange rate regime from a currency board or dollarization in DL and SGU. The distinction between country and currency risk that we introduce is crucial to differentiate a currency board and dollarization

\footnotetext{
${ }^{1}$ See also Gertler, Gilchrist, and Natalucci (2000) and Morón and Winkelried (2001).

${ }^{2}$ See Anthony and Hughes-Hallett (2000) and Goldfajn and Olivares (2000) for empirical analyses of risk premia and the pros and cons of dollarization.
} 
explicitly. In our setup, dollarization removes the currency premium, but it does not affect the steady-state level of the country premium. Dollarization affects the short-run dynamics of the country premium by removing the currency-premium terms from the estimated equation that determines those dynamics.

In CQ, dollarization implies that domestic firms have the ability to borrow also from foreign banks. Before dollarization, they are restricted to borrowing only from domestic banks. This assumption is meant to capture the financial market effects of a common currency. In our model, domestic agents can borrow from abroad both before and after dollarization. Before dollarization, they can issue bonds denominated in units of domestic currency, along with dollar denominated bonds. After dollarization, all debt must be in dollars.

CQ assumes that the domestic economy imports intermediate inputs to produce the final consumption good. Both DL and SGU allow for the presence of non-tradeables and deviations from purchasing power parity. We do not have a non-tradable sector in our model. Goods are imported for consumption purposes.

CQ and DL include optimal monetary policy in the set of regimes they consider. The issue of what monetary policy is optimal is not settled for the setup we use. Hence, as SGU, we focus on a set of rules at the core of the policy debate neither of which is necessarily optimal.

Notwithstanding obvious limitations, our assumptions capture relevant aspects of interdependence for economies that are financially fully integrated with the rest of the world, increasingly open to trade in manufactured goods, and decreasingly dependent upon exports of primary commodities. Empirical evidence suggests that the framework fits the data well in that it matches key second moments of Argentine data for reasonable parameter values.

Welfare analysis of alternative monetary regimes suggests that dollarization dominates for the benchmark parameter values we consider because it removes the volatility that originates from the currency premium. The familiar Taylor rule ranks second, better than a currency board or our version of inflation targeting. Nevertheless, a currency board matches dollarization on welfare grounds-and can do even better-if the domestic central bank holds a sufficiently large stock of foreign reserves on average.

The paper is organized as follows. Section 2 presents our theoretical model of a small, open, developing economy. Section 3 shows how the model changes under dollarization. Section 4 illustrates the monetary rules we consider. Section 5 presents our empirical model of the rest-of-the-world 
economy and risk premia. Section 6 illustrates calibration and solution and evaluates the empirical performance of the framework. Section 7 analyzes the welfare implications of alternative monetary rules. Section 8 concludes.

\section{The Model}

We use an intertemporal, open economy model that builds on Ghironi's (2000) analysis of macroeconomic interdependence under incomplete markets. This section describes the model economy when domestic currency is still in circulation. The changes implied by dollarization are illustrated in Section $3 .^{3}$

The world consists of two countries, home and foreign. Home is the emerging market economy-identified with Argentina in our empirical workand foreign is identified with the rest of the world, denoted with an asterisk. World variables are denoted with a superscript $W$. In each period $t$, the world economy is populated by a continuum of infinitely lived households between 0 and $N_{t}^{W}$. Each household consumes, supplies labor, and holds financial assets. Following Weil (1989), we assume that households are born on different dates owning no financial assets, but they own the present discounted value of their net labor income. The number of households in the home economy, $N_{t}$, grows over time at the exogenous rate $n$, i.e., $N_{t+1}=(1+n) N_{t}$. We normalize the size of a household to 1 , so that the number of households alive at each point in time is the economy's population. Foreign population grows at the same rate as home population but is assumed to be large relative to home. The world economy has existed since the infinite past. We normalize world population at time 0 to the continuum between 0 and 1 , so that $N_{0}^{W}=1$.

The current account and accumulation of net foreign assets play a role in the international transmission of shocks in our model. The birth of new households with no assets at each point in time ensures existence of a welldefined, endogenously determined steady state, to which the economy returns following temporary shocks. ${ }^{4}$

\footnotetext{
${ }^{3}$ In addition to the studies we mentioned in the introduction, see Gali and Monacelli (2000) and Parrado and Velasco (2001) for small open economy models that share some features with ours.

${ }^{4}$ Parameter restrictions such that this happens are assumed satisfied. Ghironi (2000) provides a detailed discussion of the stationarity properties of the framework. The as-
} 
At time 0, the number of goods that are supplied in the world economy is equal to the number of households. A continuum of goods $z \in[0,1]$ are produced in the world by monopolistically competitive, infinitely lived firms, each producing a single differentiated good. The number of households grows over time, but the commodity space remains unchanged. Thus, as time goes, the ownership of firms spreads over a larger number of households. Profits are distributed to consumers via dividends, and the structure of the market for each good is taken as given.

We assume that the domestic economy produces goods in the interval $[0, a]$ - which is also the size of the home population at time 0 - whereas the foreign economy produces goods in the range $(a, 1]$. Because the ratio $N_{t} / N_{t}^{*}$ is constant, it is always equal to $a /(1-a)$. As $N_{t} / N_{t}^{*}$ is small, home's share of goods supplied and consumed is small.

The asset menu includes money balances, bonds, and shares. Home households hold domestic currency bonds, domestic bonds denominated in dollars, domestic money balances, dollar balances, and shares in domestic firms. Foreign households hold dollar balances, bonds issued in the home economy, dollar denominated bonds issued by foreign agents, and shares in foreign firms. (Thus, there is no international trade in shares and domestic households are prevented from holding foreign bonds for reasons explained below.) Holdings of bonds issued by home are subject to country and currency risk premia determined in international financial markets.

Central banks conduct monetary policy by setting the domestic interest rate according to reaction functions specified below. The domestic central bank holds foreign bonds to back its money supply.

Governments consume goods in a purely dissipative manner. The government consumption index takes the same form as the private sector's in each country. Households are subject to lump-sum taxation. Governments are assumed to act as price takers and their demand functions for individual goods have the same form as the private sector's. For simplicity, we assume that all bonds issued by the domestic government are held by domestic consumers.

sumption that newborn households have no financial assets is crucial for the steady state to be determinate and the model stationary. We omit the details on the solution for the steady state. They are available upon request. 


\subsection{Consumer Behavior and Risk Premia}

Consumers have identical preferences over a real consumption index $(C)$, leisure $(L E)$, and real domestic currency and dollar balances $-M / P$ and $\varepsilon M^{\$} / P$ respectively, where $M\left(M^{\$}\right)$ denotes nominal domestic currency (dollar) balances, $\varepsilon$ is the domestic currency price of one dollar, and $P$ is the consumer price deflator. At any time $t_{0}$, the representative home consumer $j$ born in period $v \in\left[-\infty, t_{0}\right]$ maximizes the intertemporal utility function:

$U_{t_{0}}^{v^{j}}=\sum_{t=t_{0}}^{\infty} \beta^{t-t_{0}}\left\{\frac{\left[\left(C_{t}^{v^{j}}\right)^{\rho}\left(L E_{t}^{v^{j}}\right)^{1-\rho}\right]^{1-\frac{1}{\sigma}}}{1-\frac{1}{\sigma}}+\chi \frac{\left(\frac{M_{t}^{v^{j}}}{P_{t}}\right)^{1-\frac{1}{\sigma}}}{1-\frac{1}{\sigma}}+\chi^{\$} \frac{\left(\frac{\varepsilon_{t} M_{t}^{\$ v^{j}}}{P_{t}}\right)^{1-\frac{1}{\sigma}}}{1-\frac{1}{\sigma}}\right\}$,

with $\chi, \chi^{\$}$, and $\sigma$ all strictly positive and $0<\rho<1 .^{5}$

The consumption index for the representative domestic consumer is:

$$
C_{t}^{v^{j}}=\left[a^{\frac{1}{\omega}}\left(C_{H t}^{v^{j}}\right)^{\frac{\omega-1}{\omega}}+(1-a)^{\frac{1}{\omega}}\left(C_{F t}^{v^{j}}\right)^{\frac{\omega-1}{\omega}}\right]^{\frac{\omega}{\omega-1}} \quad(\omega>o),
$$

where $\omega$ is the intratemporal elasticity of substitution between consumption of domestic and foreign goods. The consumption sub-indexes that aggregate individual domestic and foreign goods are, respectively:

$$
C_{H t}^{v^{j}}=\left[\left(\frac{1}{a}\right)^{\frac{1}{\theta}} \int_{0}^{a}\left(c_{t}^{v^{j}}(z)\right)^{\frac{\theta-1}{\theta}} d z\right]^{\frac{\theta}{\theta-1}} \quad(\theta>1),
$$

and

$$
C_{F t}^{v^{j}}=\left[\left(\frac{1}{1-a}\right)^{\frac{1}{\theta}} \int_{a}^{1}\left(c_{* t}^{v^{j}}(z)\right)^{\frac{\theta-1}{\theta}} d z\right]^{\frac{\theta}{\theta-1}},
$$

where $c_{* t}^{v^{j}}(z)$ denotes time $t$ consumption of good $z$ produced in the foreign country, and $\theta$ is the elasticity of substitution across goods produced inside each country. ${ }^{6}$

\footnotetext{
${ }^{5}$ We restrict the intertemporal elasticity of substitution in utility from money holdings (domestic currency and dollars) to equal the elasticity of substitution in utility from consumption and leisure as this makes it possible to aggregate the money demand equations across generations easily.

${ }^{6} \mathrm{An}$ interior equilibrium with a positive level of output requires $\theta>1$.
} 
The deflator for nominal money balances is the consumption-based money price index (CPI):

$$
P_{t}=\left[a P_{H t}^{1-\omega}+(1-a) P_{F t}^{1-\omega}\right]^{\frac{1}{1-\omega}}
$$

where $P_{H}\left(P_{F}\right)$ is the price sub-index for home (foreign)-produced goodsboth expressed in units of the home currency. Letting $p_{t}(z)$ be the home currency price of good $z$, we have:

$$
\begin{aligned}
& P_{H t}=\left(\frac{1}{a} \int_{0}^{a}\left(p_{t}(z)\right)^{1-\theta} d z\right)^{\frac{1}{1-\theta}} \\
& P_{F t}=\left(\frac{1}{1-a} \int_{a}^{1}\left(p_{t}(z)\right)^{1-\theta} d z\right)^{\frac{1}{1-\theta}} .
\end{aligned}
$$

We assume that there are no impediments to trade and that firms do not engage in local currency pricing (i.e., pricing in the currency of the economy where goods are sold). Hence, the law of one price holds for each individual good and $p_{t}(z)=\varepsilon_{t} p_{t}^{*}(z)$, where $p_{t}^{*}(z)$ is the dollar price of good $z$. Given this hypothesis, and assuming identical intratemporal consumer preferences across countries, consumption-based purchasing power parity (PPP) holds, i.e., $P_{t}=\varepsilon_{t} P_{t}^{*}$. $^{7}$

Workers supply labor $(L)$ in competitive labor markets. The total amount of time available in each period is normalized to 1 , so that:

$$
L E_{t}^{v^{j}}=1-L_{t}^{v^{j}}
$$

The representative home consumer enters a period holding nominal bonds, nominal money balances, and shares purchased in the previous period. She or he receives interests and dividends on these assets, may earn capital gains or incur losses on shares, earns labor income, is taxed, and consumes.

Denote the date $t$ price (in units of domestic currency) of a claim to the representative domestic firm $i$ 's entire future profits (starting on date $t+1$ )

\footnotetext{
${ }^{7} \mathrm{Hau}$ (2000) finds evidence of an inverse relationship between the import share of an economy and real exchange rate volatility. PPP in our model is consistent with his result, as the world consumption basket consists mainly of foreign goods. Obstfeld (1998) provides evidence that PPP seems to hold more accurately for developing economies, the nominal exchange rate being significantly more volatile than the real exchange rate. The link between exchange rates and import prices is stronger in emerging market economies than for OECD countries (Takagi and Yoshida, 1999).
} 
by $V_{t}^{i}$. Let $x_{t+1}^{v^{j i}}$ be the share of the representative domestic firm $i$ owned by the representative domestic consumer $j$ born in period $v$ at the end of period $t$. $D_{t}^{i}$ denotes the nominal dividends firm $i$ issues on date $t$. Then, letting $A_{t+1}^{v^{j}}\left(A_{t+1}^{\$ v^{j}}\right)$ be the home consumer's holdings of domestic currency (dollar) denominated bonds entering time $t+1$, the period budget constraint expressed in units of domestic currency is:

$$
\begin{aligned}
& A_{t+1}^{v^{j}}+\varepsilon_{t} A_{t+1}^{\$ v^{j}} \\
& +\int_{0}^{a}\left(V_{t}^{i} x_{t+1}^{v^{j i}}-V_{t-1}^{i} x_{t}^{v^{j i}}\right) d i+M_{t}^{v^{j}}+\varepsilon_{t} M_{t}^{\$ v^{j}} \\
= & \left(1+i_{t}^{H}\right) A_{t}^{v^{j}}+\varepsilon_{t}\left(1+i_{t}^{\$}\right) A_{t}^{\$ v^{j}}-\tau_{t}^{\$}\left(1+i_{t}^{H}\right) A_{t}^{v^{j}} \\
& +\int_{0}^{a} D_{t}^{i} x_{t}^{v^{j i}} d i+\int_{0}^{a}\left(V_{t}^{i}-V_{t-1}^{i}\right) x_{t}^{v^{j i}} d i \\
& +M_{t-1}^{v^{j}}+\varepsilon_{t} M_{t-1}^{\$ v^{j}}+W_{t} L_{t}^{v^{j}}-P_{t} C_{t}^{v^{j}}-P_{t} T_{t},
\end{aligned}
$$

where $W_{t}$ is the nominal wage, $M_{t-1}^{v^{j}}$ and $\varepsilon_{t} M_{t-1}^{\$ v^{j}}$ are the agent's holdings of nominal money balances entering period $t$, and $T_{t}$ is a lump-sum net real transfer. ${ }^{8}$

For any given gross return $1+i_{t}^{H}$ between $t-1$ and $t, \tau_{t}^{\$} \in[0,1]$ captures the extent to which holdings of domestic currency bonds are less attractive to the agent. We think of $\tau_{t}^{\$}\left(1+i_{t}^{H}\right) A_{t}^{v^{j}}$ as a simple specification for a timevarying transaction cost of holding domestic currency bonds. $\tau_{t}^{\$}$ acts as a "tax" rate on the gross return on the stock $A_{t}^{v^{j}}$, so that $\left(1-\tau_{t}^{\$}\right)\left(1+i_{t}^{H}\right)$ is the gross return on holdings of domestic currency bonds between $t-1$ and $t$ net of the tax, which is known at time $t-1$.

The representative domestic consumer maximizes intertemporal utility subject to the constraints (1) and (2). Dropping the $j$ superscript (because symmetric agents make identical choices in equilibrium), optimal labor supply is given by:

$$
L_{t}^{v^{j}}=1-L E_{t}^{v^{j}}=1-\frac{1-\rho}{\rho} \frac{C_{t}^{v}}{W_{t} / P_{t}},
$$

which equates the marginal cost of supplying labor to the marginal utility of consumption generated by the corresponding increase in labor income.

Making use of this equation, the first-order condition for the optimal

\footnotetext{
${ }^{8}$ Given that individuals are born owning no financial wealth, because not linked by altruism to individuals born in previous periods, $A_{v}^{v^{j}}=A_{v}^{\$ v^{j}}=x_{v}^{v^{j i}}=M_{v-1}^{v^{j}}=M_{v-1}^{\$ v^{j}}=0$.
} 
holdings of domestic currency bonds yields the Euler condition:

$$
C_{t}^{v}=\beta^{-\sigma}\left[\left(1-\tau_{t+1}^{\$}\right)\left(1+i_{t+1}^{H}\right)\left(\frac{P_{t}}{P_{t+1}}\right)\right]^{-\sigma}\left[\left(\frac{W_{t}}{P_{t}} / \frac{W_{t+1}}{P_{t+1}}\right)\right]^{-(1-\rho)(1-\sigma)} C_{t+1}^{v}
$$

for all $v \leq t$. Unless $\sigma=1$-in which case period utility is additively separable in consumption and leisure-consumption growth depends on real wage growth. Depending on whether $\sigma$ is smaller or larger than 1, even in the special case in which $\beta\left[\left(1-\tau_{t+1}^{\$}\right)\left(1+i_{t+1}^{H}\right)\left(P_{t} / P_{t+1}\right)\right]=1$, real wage growth will introduce an upward or downward tilt in the consumption path. For any level of the interest rate $i^{H}$, a lower value of $\tau^{\$}$ makes saving more attractive, and causes future consumption to rise relative to current.

From the first-order condition for the optimal holding of domestic currency, demand for home currency real balances is given by:

$$
\frac{M_{t}^{v}}{P_{t}}=\left(\frac{\chi}{\rho}\right)^{\sigma} C_{t}^{v}\left[\frac{\left(1-\tau_{t+1}^{\$}\right)\left(1+i_{t+1}^{H}\right)}{\left(1-\tau_{t+1}^{\$}\right)\left(1+i_{t+1}^{H}\right)-1}\right]^{\sigma}\left(\frac{1-\rho}{\rho W_{t} / P_{t}}\right)^{(1-\rho)(1-\sigma)} .
$$

Real domestic currency balances increase with consumption and decrease with the opportunity cost of holding money. Ceteris paribus, if $\tau^{\$}$ falls, demand for real balances falls, because holding bonds is relatively more profitable. The impact of a higher real wage depends on $\sigma$. If $\sigma<1$, a higher real wage causes demand for real balances to decrease for any given level of consumption.

Demand for real dollar balances is:

$$
\frac{\varepsilon_{t} M_{t}^{\$ v}}{P_{t}}=\left(\frac{\chi^{\$}}{\rho}\right)^{\sigma} C_{t}^{v}\left(\frac{1+i_{t+1}^{\$}}{i_{t+1}^{\$}}\right)^{\sigma}\left(\frac{1-\rho}{\rho W_{t} / P_{t}}\right)^{(1-\rho)(1-\sigma)} .
$$

Holdings of real dollar balances depend on the opportunity cost of holding cash rather than dollar denominated assets.

Condition (4) can be combined with the first-order condition for holdings of dollar-denominated bonds to yield a no-arbitrage condition between domestic currency and dollar bonds for domestic agents. Absence of unexploited arbitrage opportunities requires:

$$
1+i_{t+1}^{H}=\frac{\left(1+i_{t+1}^{\$}\right)}{1-\tau_{t+1}^{\$}} \frac{\varepsilon_{t+1}}{\varepsilon_{t}}
$$


The closer $\tau_{t+1}^{\$}$ to one, the higher $i_{t+1}^{H}$ must be to make agents indifferent between holding domestic currency and dollar bonds. ${ }^{9}$

Now consider foreign agents' behavior. Let $A^{*}$ denote holdings of dollar bonds issued in the foreign economy. A subscript $*$ refers to foreign agents' bond holdings. The portion of the representative foreign agent's period budget constraint involving bond holdings can be written as:

$$
\begin{aligned}
& \frac{1}{\varepsilon_{t}} A_{* t+1}^{v^{j}}+A_{* t+1}^{\$ v^{j}}+A_{* t+1}^{* v^{j}}+\ldots \\
= & \frac{1}{\varepsilon_{t}}\left(1+i_{t}^{H}\right) A_{* t}^{v^{j}}-\frac{\tau_{t}^{\$^{*}}}{\varepsilon_{t}}\left(1+i_{t}^{H}\right) A_{* t}^{v^{j}} \\
& +\left(1+i_{t}^{\$}\right) A_{* t}^{\$ v^{j}}-\tau_{t}^{H^{*}}\left(1+i_{t}^{\$}\right) A_{* t}^{\$^{j}} \\
& +\left(1+i_{t}^{*}\right) A_{* t}^{* v^{j}}+\ldots,
\end{aligned}
$$

with $\tau_{t}^{\$^{*}}, \tau_{t}^{H^{*}} \in[0,1]$. The total transaction cost paid by foreign agents to hold home, dollar denominated (home currency denominated) bonds in the amount $A_{* t}^{\$ \delta^{j}}\left(A_{* t}^{v^{j}}\right)$ between $t-1$ and $t$ is $\tau_{t}^{H^{*}}\left(1+i_{t}^{\$}\right) A_{* t}^{\$ v^{j}}\left(\frac{\tau_{t}^{\mho^{*}}}{\varepsilon_{t}}\left(1+i_{t}^{H}\right) A_{* t}^{v^{j}}\right)$. The "after tax" gross returns on holdings of home bonds by foreign agents are $\frac{1-\tau_{t}^{\$^{*}}}{\varepsilon_{t}}\left(1+i_{t}^{H}\right)$ and $\left(1-\tau_{t}^{H^{*}}\right)\left(1+i_{t}^{\$}\right)$. For foreign agents to be indifferent across different types of bonds, it must be:

$$
\begin{aligned}
& 1+i_{t+1}^{*}=\left(1-\tau_{t+1}^{\$^{*}}\right)\left(1+i_{t+1}^{H}\right) \frac{\varepsilon_{t}}{\varepsilon_{t+1}}, \\
& 1+i_{t+1}^{*}=\left(1-\tau_{t+1}^{H^{*}}\right)\left(1+i_{t+1}^{\$}\right),
\end{aligned}
$$

which imply:

$$
1+i_{t+1}^{H}=\frac{1-\tau_{t+1}^{H^{*}}}{1-\tau_{t+1}^{\$ *}}\left(1+i_{t+1}^{\$}\right) \frac{\varepsilon_{t+1}}{\varepsilon_{t}} .
$$

Ceteris paribus, the closer $\tau_{t+1}^{\$^{*}}\left(\tau_{t+1}^{H^{*}}\right)$ to one, the higher the interest rate $i_{t+1}^{H}$ $\left(i_{t+1}^{\$}\right)$ must be for foreign agents to be willing to hold home bonds along with foreign dollar bonds.

\footnotetext{
${ }^{9}$ If the household is issuing bonds rather than accumulating assets $(A<0)$, the presence of $\tau^{\$}$ implies that (ceteris paribus) the household would like to issue bonds in domestic currency, as the "after tax" cost is lower. In equilibrium, interest rates adjust to make the household indifferent.
} 
No-arbitrage conditions (7)-(10) imply restrictions on the "tax" factors $\tau_{t+1}^{\$}, \tau_{t+1}^{\$^{*}}$, and $\tau_{t+1}^{H^{*}}$, which must be satisfied to ensure consistency of noarbitrage across markets. It must be

$$
\frac{1-\tau_{t+1}^{H^{*}}}{1-\tau_{t+1}^{\$^{*}}}=\frac{1}{1-\tau_{t+1}^{\$}}
$$

The wedge $1-\tau_{t+1}^{H^{*}}$ between $1+i_{t+1}^{*}$ and $1+i_{t+1}^{\$}$ in equation (9) reflects issuingcountry considerations in the eyes of foreign investors. Letting $p_{t+1}^{H} \equiv 1-\tau_{t+1}^{H^{*}}$ denote a country discount factor between $t$ and $t+1$, the restriction (11) can be rewritten as $1-\tau_{t+1}^{\$^{*}}=p_{t+1}^{H}\left(1-\tau_{t+1}^{\$}\right)$. Now, the wedge $1-\tau_{t+1}^{\$^{*}}$ between $1+i_{t+1}^{*}$ and $\left(1+i_{t+1}^{H}\right) \frac{\varepsilon_{t}}{\varepsilon_{t+1}}$ in equation (8) reflects country and currency considerations. We can thus define a currency discount factor $p_{t+1}^{\$} \equiv 1-$ $\tau_{t+1}^{\$}$ that captures both the "tax" on domestic agents' holdings of domestic currency assets rather than dollar assets and the portion of the "tax" on foreign agents' holdings of home bonds denominated in home currency that is not directly attributable to country considerations. Using these definitions, the following no-arbitrage conditions must hold in the bond market:

$$
\begin{aligned}
1+i_{t+1}^{H} & =\frac{\left(1+i_{t+1}^{\$}\right)}{p_{t+1}^{\$}} \frac{\varepsilon_{t+1}}{\varepsilon_{t}} \\
1+i_{t+1}^{\$} & =\frac{1+i_{t+1}^{*}}{p_{t+1}^{H}}
\end{aligned}
$$

and

$$
1+i_{t+1}^{H}=\frac{\left(1+i_{t+1}^{*}\right)}{p_{t+1}^{H} p_{t+1}^{\$}} \frac{\varepsilon_{t+1}}{\varepsilon_{t}} .
$$

The country "risk" premium that issuers of domestic, dollar-denominated bonds must pay for foreign agents to be willing to hold those bonds is $\frac{1}{p_{t+1}^{H}} \geq$ 1 ; the currency premium (above and beyond expected depreciation of the domestic currency) is $\frac{1}{p_{t+1}^{\$}} \geq 1$. We do not model the determination of these variables formally. In Section 5 we describe a plausible empirical model of the dynamics of $p_{t+1}^{H}$ and $p_{t+1}^{\$}$ and the procedure for measuring the latter from the data. ${ }^{10}$

\footnotetext{
${ }^{10}$ Given that we work in a perfect foresight setup, it would be formally more appropriate to refer to $\frac{1}{p^{H}}$ and $\frac{1}{p^{\S}}$ as country and currency spreads, respectively, rather than risk premia
} 
At this point, we can motivate the restriction that domestic agents do not hold foreign bonds. In the perfect foresight framework of this paper, if domestic agents can arbitrage across all three bonds, two possibilities arise, depending on the specification adopted: either restrictions on the "tax factors" along the lines of (11) require premia to be zero when no-arbitrage conditions are satisfied for both domestic and foreign bond holders, or premia turn out to be neutral, in the sense that shocks to country and/or currency premia have no impact on the domestic economy unless they affect the foreign interest rate. ${ }^{11}$ Even though it has happened in the recent past that shocks to premia for emerging markets propagate to more mature markets (including the U.S. money market) via international financial spillovers, there is no clear evidence of such a systematic causal relation. Hence, we see the restriction we impose on private domestic bond holdings as a simple way to remove neutrality of premia. ${ }^{12} 13$

It is easy to verify that shocks to $p_{t+1}^{H}$ are not neutral under our assumptions. For given foreign interest rate and under a fixed exchange rate regime,

in a traditional sense (which are determined by second moments of the relevant variables in models with uncertainty and rational expectations). Because we model the determination of $p^{H}$ and $p^{\$}$ empirically rather than theoretically, we choose not to worry too much about this semantic issue. In practice, our estimated equations for the two spreads will reflect both transaction cost effects as in our model and the role of uncertainty in reality. As the numerical solution of the overall framework is equivalent to that of a log-linear rational expectation setup and the two spreads are subject to exogenous shocks, the semantic issue has no bearing on our results.

${ }^{11}$ Details are available on request. The second specification was explored in an earlier version of the paper, available at http://www2.bc.edu/ ghironi/research.html.

${ }^{12}$ The assumption that the domestic central bank holds foreign bonds to back its money supply has no consequence for the non-neutrality of premia. Note that the restriction does not necessarily conflict with the idea of a fully liberalized capital account as domestic agents are free to hold cash balances in dollars.

${ }^{13}$ It may be argued that the restriction we impose amounts to stacking the deck in favor of dollarization by introducing an artificial channel through which premia (in particular, the currency premium) matter. The assumption that only a fraction of domestic households do not hold foreign bonds would perhaps be more realistic. Nevertheless, it should be noted that we do not take an a priori stance on the relation between currency and country premium. We let their processes be revealed by the data below. Hence, we leave the possibility that removing the currency premium may have negative effects on the country premium open. Because the currency premium matters only in so far as it affects the country premium (see below), we believe there is no pro-dollarization deck-stacking in what we do. If anything, our choice to abstract from balance sheet effects (traditionally pointed to as a source of gains from dollarization) stacks the cards against dollarization. 
exogenous shocks to the currency premium $p_{t+1}^{\$}$ are neutral, unless movements in $p_{t+1}^{\$}$ cause movements in the country premium $p_{t+1}^{H}$, which alter the value of $i_{t+1}^{\$}$. If the latter does not move, changes in $p_{t+1}^{\$}$ will be offset by movements of $i_{t+1}^{H}$ to keep $p_{t+1}^{\$}\left(1+i_{t+1}^{H}\right)=1+i_{t+1}^{\$}$, as required by $(12)$ under fixed exchange rates. However, as we shall see below, the data point to strong interdependence between $p_{t+1}^{\$}$ and $p_{t+1}^{H}$, ensuring non-neutrality of the currency premium under a currency board.

Absence of arbitrage opportunities between bonds and shares in the domestic economy requires:

$$
p_{t+1}^{\$}\left(1+i_{t+1}^{H}\right)=\frac{D_{t+1}^{i}+V_{t+1}^{i}}{V_{t}^{i}} .
$$

The interest rate must rise above the level implied by current dividends and current and future share prices to ensure indifference between bonds and shares.

Letting $r_{t+1}^{*}$ denote the foreign consumption-based real interest rate between $t$ and $t+1$, the familiar Fisher parity condition ensures that:

$$
1+r_{t+1}^{*}=\left(1+i_{t+1}^{*}\right) \frac{P_{t}^{*}}{P_{t+1}^{*}}=\frac{1+i_{t+1}^{*}}{1+\pi_{t+1}^{C P I^{*}}},
$$

where $\pi_{t+1}^{C P I^{*}}$ is foreign CPI inflation. Dividing both sides of (14) by $1+\pi_{t+1}^{C P I}$ (which is equal to $P_{t+1} / P_{t}$ ) and making use of PPP yields:

$$
1+r_{t+1}=\frac{1+r_{t+1}^{*}}{p_{t+1}^{H} p_{t+1}^{\$}}
$$

where

$$
1+r_{t+1}=\frac{1+i_{t+1}^{H}}{1+\pi_{t+1}^{C P I}}
$$

The presence of risk premia causes the home real interest rate to be above the world real rate. ${ }^{14}$

\section{$2.2 \quad$ Firms}

Because we focus on high frequency business cycles and use monthly data in our empirical work, we abstract from accumulation of physical capital and

\footnotetext{
${ }^{14}$ As usual, first-order conditions and the period budget constraint must be combined with appropriate transversality conditions to ensure optimality.
} 
assume that labor is the only factor of production. We assume that labor employed today generates output available for sale only at time $t+\nu$. It takes time for goods to be distributed and sold on the markets, so that there is a discrepancy between the time when labor costs are borne by firms and the time when that labor actually generates revenues. We find this consistent with the time horizon of our exercise. The lag in the sales process introduces a further channel through which interests rates and risk premia affect the economy. $^{15}$ is: ${ }^{16}$

Output supplied for sale at time $t$ by the representative domestic firm $i$

$$
Y_{t}^{\mathrm{Si}}=Z_{t-\nu} L_{t-\nu}^{i}
$$

Labor employed by firm $i$ at time $t-\nu$, which generates output available for sale at time $t$, is $L_{t-\nu}^{i} . Z_{t-\nu}$ measures economy-wide exogenous shocks to labor productivity that took place at the time when labor was employed.

Output demand comes from several sources: domestic and foreign consumers; domestic and foreign governments; and domestic and foreign firms. The demand for home good $z$ by the representative home consumer born in period $v$ is:

$$
c_{t}^{v}(z)=\left(\frac{p_{t}(z)}{P_{H t}}\right)^{-\theta}\left(\frac{P_{H t}}{P_{t}}\right)^{-\omega} C_{t}^{v},
$$

obtained by maximizing $C^{v}$ subject to a spending constraint. Total demand for home good $z$ coming from domestic consumers is: ${ }^{17}$

$c_{t}(z)=a\left[\begin{array}{c}\cdots \frac{n}{(1+n)^{t+1}} c_{t}^{-t}(z)+\ldots+\frac{n}{(1+n)^{2}} c_{t}^{-1}(z)+\frac{n}{1+n} c_{t}^{0}(z) \\ +n c_{t}^{1}(z)+n(1+n) c_{t}^{2}(z)+\cdots+n(1+n)^{t-1} c_{t}^{t}(z)\end{array}\right]$

\footnotetext{
${ }^{15}$ Neumeyer and Perri (2000) assume that workers must be paid one period in advance to generate a similar effect.

${ }^{16}$ Because all firms in the world economy are born in period $-\infty$, after which no new goods appear, it is not necessary to index output and factor demands by the firms' date of birth.

${ }^{17}$ At time 0 , home population is equal to $a$. At time 1 , it is $a(1+n)$. Hence, generation 1 consists of an households. Population at time 2 is $a(1+n)^{2}$. It follows that generation 2 consists of an $(1+n)$ households. Continuing with this reasoning shows that generation $t$ consists of $a n(1+n)^{t-1}$ households. Going back in time from $t=0$, population at time -1 is $\frac{a}{1+n}$. Hence, generation 0 consists of $\frac{a n}{1+n}$ households. Population at time -2 is $\frac{a}{(1+n)^{2}}$. It follows that generation -1 consists of $\frac{a n}{(1+n)^{2}}$ households. Continuing with this reasoning makes it possible to show that generation $-t$ consists of $\frac{a n}{(1+n)^{t+1}}$ households.
} 


$$
\begin{aligned}
& =\left(\frac{p_{t}(z)}{P_{H t}}\right)^{-\theta}\left(\frac{P_{H t}}{P_{t}}\right)^{-\omega} a\left[\begin{array}{c}
\ldots \frac{n}{(1+n)^{t+1}} C_{t}^{-t}+\ldots+\frac{n}{(1+n)^{2}} C_{t}^{-1}+\frac{n}{1+n} C_{t}^{0} \\
+n C_{t}^{1}+n(1+n) C_{t}^{2}+\cdots+n(1+n)^{t-1} C_{t}^{t}
\end{array}\right] \\
& =\left(\frac{p_{t}(z)}{P_{H t}}\right)^{-\theta}\left(\frac{P_{H t}}{P_{t}}\right)^{-\omega} a(1+n)^{t} C_{t},
\end{aligned}
$$

where

$$
C_{t} \equiv \frac{a\left[\begin{array}{c}
\cdots \frac{n}{(1+n)^{t+1}} C_{t}^{-t}+\ldots+\frac{n}{(1+n)^{2}} C_{t}^{-1}+\frac{n}{1+n} C_{t}^{0} \\
+n C_{t}^{1}+n(1+n) C_{t}^{2}+\cdots+n(1+n)^{t-1} C_{t}^{t}
\end{array}\right]}{a(1+n)^{t}}
$$

is aggregate private home consumption per capita.

Given identity of intratemporal preferences, the expression for the demand of home good $z$ from foreign consumers born in period $v$ is analogous, and total demand for the same good by foreign consumers is

$$
c_{t}^{*}(z)=\left(\frac{p_{t}(z)}{P_{H t}}\right)^{-\theta}\left(\frac{P_{H t}}{P_{t}}\right)^{-\omega}(1-a)(1+n)^{t} C_{t}^{*},
$$

where

$$
C_{t}^{*} \equiv \frac{(1-a)\left[\begin{array}{c}
\cdots \frac{n}{(1+n)^{t+1}} C_{t}^{-t^{*}}+\ldots+\frac{n}{(1+n)^{2}} C_{t}^{-1^{*}}+\frac{n}{1+n} C_{t}^{0^{*}} \\
+n C_{t}^{1^{*}}+n(1+n) C_{t}^{2^{*}}+\cdots+n(1+n)^{t-1} C_{t}^{t^{*}}
\end{array}\right]}{(1-a)(1+n)^{t}}
$$

is aggregate private foreign consumption per capita.

Changing the price of its output is a source of costs for the firm, which generates nominal rigidity. Specifically, we assume that the real cost (measured in units of the composite good) of output-price inflation volatility around the steady-state level of inflation, $\bar{\pi}$, is: ${ }^{18}$

$$
P A C_{t}^{i}=\frac{\phi}{2}\left(\frac{p_{t}(i)}{p_{t-1}(i)}-1-\bar{\pi}\right)^{2} \frac{p_{t}(i)}{P_{t}} Y_{t}^{i} .
$$

When the firm changes the price of its output, material goods-e.g., new catalogs, price tags, etc.-need to be purchased. The price adjustment cost $\left(P A C^{i}\right)$ captures the amount of marketing materials that must be purchased

\footnotetext{
${ }^{18}$ The quadratic specification for the cost of adjusting prices, first introduced by Rotemberg (1982), yields dynamics for the aggregate economy that are similar to those resulting from staggered price setting a' la Calvo (1983).
} 
to implement a price change. Because the amount of these materials is likely to increase with the firm's size, $P A C^{i}$ increases with the firm's revenue $\left(\left(p_{t}(i) / P_{t}\right) Y_{t}^{i}\right)$, which is taken as a proxy for size. The cost is convex in inflation; faster price movements are more costly to the firm: more marketing activity is likely to be required to preserve demand from falling too much as a consequence of a large price increase. Symmetrically, a large price decrease gives the firm incentives to do more marketing as a way of letting a larger fraction of the public know about the lower price.

Total demand for good $i$ produced in the home country is obtained by adding the demands for that good originating in the two countries. Making use of the results above, and recalling that governments's demand functions have the same form as the private sector's, it is:

$$
Y_{t}^{D i}=\left(\frac{p_{t}(i)}{P_{H t}}\right)^{-\theta}\left(\frac{P_{H t}}{P_{t}}\right)^{-\omega} \widehat{Y}_{t}^{D W} .
$$

Using a "hat" to denote aggregate (as opposed to aggregate per capita) levels of variables, aggregate world demand of the composite good, $\widehat{Y}_{t}^{D W}$, is defined by: $\widehat{Y}_{t}^{D W} \equiv \widehat{C}_{t}^{W}+\widehat{G}_{t}^{W}+\widehat{P A} C_{t}^{W} . \widehat{C}_{t}^{W} \equiv(1+n)^{t}\left[a C_{t}+(1-a) C_{t}^{*}\right]$, $\widehat{G}_{t}^{W} \equiv(1+n)^{t}\left[a G_{t}+(1-a) G_{t}^{*}\right]$, and $\widehat{P A} C_{t}^{W} \equiv a P A C_{t}^{i}+(1-a) P A C_{t}^{* i}$ denote world private and government consumption, and the world aggregate cost of adjusting prices, respectively. ${ }^{19}$

Given the no-arbitrage condition between bonds and shares (15) and a no-speculative bubble condition, it is possible to verify that the real price of firm $i$ 's shares at time $t_{0}$ is given by the present discounted value of the real dividends paid by the firm from $t_{0}+1$ on:

$$
\frac{V_{t_{0}}^{i}}{P_{t_{0}}}=\sum_{t=t_{0}+1}^{\infty} \widetilde{R}_{t_{0}, t} \frac{D_{t}^{i}}{P_{t}}
$$

where

$$
\widetilde{R}_{t_{0}, t} \equiv\left[\prod_{u=t_{0}+1}^{t} p_{u}^{\$}\left(1+r_{u}\right)\right]^{-1}
$$

\footnotetext{
${ }^{19}$ The expression for the world aggregate cost of adjusting prices follows from the assumption that the number of firms is constant. In the expression for $\widehat{P A C}_{t}^{W}$, we have already made use of the fact that symmetric firms make identical equilibrium choices. We retained the $i$ superscript for individual firms' costs to economize on notation in what follows. Firms are not indexed by their date of birth. Keeping the $i$ superscript for individual firms' variables allows us to denote aggregate per capita variables referring to firms by dropping the superscript.
} 
denotes the risk-adjusted interest rate factor, and $\widetilde{R}_{t_{0}, t_{0}}=1$.

At time $t_{0}$, firm $i$ maximizes:

$$
\frac{V_{t_{0}}^{i}+D_{t_{0}}^{i}}{P_{t_{0}}}=\sum_{t=t_{0}}^{\infty} \widetilde{R}_{t_{0}, t} \frac{D_{t}^{i}}{P_{t}}
$$

i.e., the present discounted value of dividends to be paid from $t_{0}$ on. At each point in time, real dividends are given by the difference between revenues$\left(p_{t}(i) / P_{t}\right) Y_{t}^{i}$-and costs- $-\left(W_{t} / P_{t}\right) L_{t}^{i}+P A C_{t}^{i}$. The firm chooses the price of its product and the amount of labor demanded in order to maximize the present discounted value of its current and future profits subject to the constraints (19) and (20), and the market clearing condition $Y_{t}^{i}=Y_{t}^{\mathrm{Si}}=Y_{t}^{D i}$. Firm $i$ takes the aggregate price index, the wage rate, $Z$, and world aggregates as given.

Let $\lambda_{t}^{i}$ denote the Lagrange multiplier on the constraint $Y_{t}^{\mathrm{Si}}=Y_{t}^{D i}$. Then, $\lambda_{t}^{i}$ is the shadow price of an extra unit of output to be sold in period $t$, or the marginal cost of time $t$ sales. The first-order condition with respect to $p_{t}(i)$ yields the pricing equation:

$$
p_{t}(i)=\Psi_{t}^{i} P_{t} \lambda_{t}^{i}
$$

which equates the price charged by firm $i$ to the product of the (nominal) shadow value of one extra unit of output-the (nominal) marginal cost $\left(P_{t} \lambda_{t}^{i}\right)$ and a markup $\left(\Psi_{t}^{i}\right)$. The latter depends on output demand as well as on the impact of today's pricing decision on today's and tomorrow's costs of adjusting the output price:

$$
\Psi_{t}^{i} \equiv \theta Y_{t}^{i}\left\{(\theta-1) Y_{t}^{i}\left[1-\frac{\phi}{2}\left(\frac{p_{t}(i)}{p_{t-1}(i)}-1-\bar{\pi}\right)^{2}\right]+\phi \Upsilon_{t}\right\}^{-1},
$$

where

$$
\begin{aligned}
\Upsilon_{t} \equiv & Y_{t}^{i} \frac{p_{t}(i)}{p_{t-1}(i)}\left(\frac{p_{t}(i)}{p_{t-1}(i)}-1-\bar{\pi}\right) \\
& -\frac{Y_{t+1}^{i}}{p_{t+1}^{\Phi}\left(1+r_{t+1}\right)} \frac{P_{t}}{P_{t+1}}\left(\frac{p_{t+1}(i)}{p_{t}(i)}\right)^{2}\left(\frac{p_{t+1}(i)}{p_{t}(i)}-1-\bar{\pi}\right) .
\end{aligned}
$$

Firms react to CPI dynamics in their pricing decisions. Different monetary rules yield different CPI inflation dynamics. Hence, they affect producer 
prices and the markup. Through this channel, they generate different dynamics of relative prices and the real economy. ${ }^{20}$

If $\phi=0$, i.e., if prices are fully flexible, $\Psi_{t}^{i}=\theta /(\theta-1)$, the familiar constant-elasticity markup. If $\phi \neq 0$, introducing price rigidity generates endogenous fluctuations of the markup. ${ }^{21}$

The first-order condition for the optimal choice of $L_{t}^{i}$ yields:

$$
\frac{W_{t}}{P_{t}}=\widetilde{R}_{t, t+\nu} \lambda_{t+\nu}^{i} Z_{t}
$$

Today's real wage must equal the discounted shadow value of the extra output for sale at time $t+\nu$ produced by an additional unit of labor employed at $t$. Denoting the real wage index $\left(\frac{W_{t}}{P_{t}}\right)$ with $w_{t}$, using $L A G^{\nu}$ to denote the lag operator applied $\nu$ times, and rearranging we obtain:

$$
\lambda_{t}^{i}=\left(L A G^{\nu} \widetilde{R}_{t, t+\nu}^{-1}\right) \frac{w_{t-\nu}}{Z_{t-\nu}} .
$$

Thus, at an optimum, the shadow value of output sold today must equal the productivity adjusted marginal cost borne $t-\nu$ periods ago compounded by the real, risk-adjusted interest factor.

Making use of the market clearing conditions $Y_{t}^{\mathrm{Si}}=Y_{t}^{D i}$ and $\widehat{Y}_{t}^{D W}=$ $\widehat{Y}_{t}^{S W}=\widehat{Y}_{t}^{W}$, of the expressions for supply and demand of good $i$, and recalling that symmetric firms make identical equilibrium choices ( so that $\left.p_{t}(i)=P_{H t}\right)$ yields:

$$
L_{t}^{i}=\left(\frac{p_{t+\nu}(i)}{P_{t+\nu}}\right)^{-\omega} \frac{\hat{Y}_{t+\nu}^{W}}{Z_{t}} .
$$

Because labor employed today generates revenue only $\nu$ periods into the future, firms adjust labor demand in a forward looking manner, reacting to

\footnotetext{
${ }^{20}$ The role of markup fluctuations in the business cycle has been explored and documented extensively in Rotemberg and Woodford (1999).

${ }^{21}$ If $\theta$ approaches infinity, firms have no monopoly power (assuming that all variables in $\Psi_{t}^{i}$ have well defined limit values), and the markup reduces to the competitive level:

$$
\Psi_{t}^{i}=\frac{1}{1-\frac{\phi}{2}\left(\frac{p_{t}(i)}{p_{t-1}(i)}-1-\bar{\pi}\right)^{2}} .
$$

Note that, if the economy is not in steady state, the competitive markup is still affected by the degree of nominal rigidity (even if firms are no longer active price setters) because a change in prices acts as a tax on firms' revenues due to the specification of the price adjustment cost.
} 
expected changes in real prices and world demand, adjusted by productivity. This equation can be combined with (21) and (23) to obtain:

$$
L_{t}^{i}=\left(\widetilde{R}_{t, t+\nu}^{-1} \Psi_{t+\nu}^{i} w_{t}\right)^{-\omega} \widehat{Y}_{t+\nu}^{W} Z_{t}^{\omega-1}
$$

showing that today's labor demand reacts to the interest adjusted future markup on the cost of labor employed today.

Given agents' optimality conditions and constraints, it is possible to obtain the equations that govern the behavior of aggregate per capita variables following the aggregation procedure illustrated for the case of consumption demand. We omit the details of the aggregation procedure and refer the interested reader to Ghironi (2000) for an illustrative example in a simpler setup. In the next sub-section, we present the equations that govern the dynamics of aggregate per capita net foreign asset holdings in the economy.

\subsection{The Law of Motion for Domestic Assets}

Appendix A describes the derivation of the law of motion for domestic aggregate per capita net foreign assets in detail. We report the main equations here.

Domestic consumers' aggregate per capita real assets entering period $t$ $\left(a s c_{t}\right)$ consist of net foreign bond holdings $\left(a s_{t}\right)$ and the real equity value of the home economy entering the same period $\left(v_{t-1} \equiv \frac{V_{t-1}}{P_{t-1}}\right){ }^{22}$

$$
a s c_{t}=a s_{t}+v_{t-1}
$$

The equity value of the economy obeys:

$$
v_{t}=\frac{1+n}{p_{t+1}^{\$}\left(1+r_{t+1}\right)} v_{t+1}+\frac{d_{t+1}}{p_{t+1}^{\$}\left(1+r_{t+1}\right)},
$$

where $d$ denotes aggregate per capita real dividends:

$$
d_{t}=Y_{t}-w_{t} L_{t}-\frac{\phi}{2}\left(\pi_{t}^{P P I}-\bar{\pi}\right)^{2} Y_{t}
$$

\footnotetext{
${ }^{22}$ Because we prevent domestic consumers from holding foreign bonds, net foreign bond holdings as are always negative in our model.
} 
( $Y$ is aggregate per capita GDP in units of the consumption basket ${ }^{23}, L$ is aggregate per capita labor demand, and $\pi_{t}^{P P I}$ is producer price inflation at time $\left.t: \pi_{t}^{P P I} \equiv \frac{p_{t}(i)}{p_{t-1}(i)}-1\right)$.

The domestic private sector's net foreign assets entering period $t$ are obtained by aggregating asset holdings of consumers and firms. Because shares are a liability of firms towards consumers, it follows that private net foreign assets are the difference between consumers' assets $\left(a s c_{t}\right.$, which include equity) and the equity value of the home economy entering the same period $\left(v_{t-1}\right)$. In other words, domestic private net foreign assets coincide with the consumers' net foreign bond holdings $\left(a s_{t}\right)$.

We denote aggregate per capita real official reserves with $r e s_{t+1}$. When money supply is backed only by holdings of official reserves, the relation between real money supply (which must equal demand in equilibrium) and reserves is:

$$
m_{t}-\frac{m_{t-1}}{\left(1+\pi_{t}^{C P I}\right)(1+n)}=(1+n) \operatorname{res}_{t+1}-\frac{1+e_{t}}{1+\pi_{t}^{C P I}} \text { res }_{t},
$$

where $m_{t} \equiv \frac{M_{t}}{P_{t}}$ and $1+e_{t} \equiv \frac{\varepsilon_{t}}{\varepsilon_{t-1}}$. Real money demand is determined by the aggregate per capita version of equation (5).

Appendix A shows that the law of motion for the home country's aggregate per capita real net foreign assets (private and official) is:

$$
\begin{aligned}
& (1+n) a s_{t+1}+(1+n) \operatorname{res}_{t+1} \\
= & p_{t}^{\$}\left(1+r_{t}\right) a s_{t}+p_{t}^{\$}\left(1+r_{t}\right) r e s_{t}+Y_{t}-C_{t}-G_{t}-\frac{\phi}{2}\left(\pi_{t}^{P P I}-\bar{\pi}\right)^{2} Y_{t},
\end{aligned}
$$

where $G$ is aggregate government consumption per capita.

Equations (25)-(29) describe the dynamics of private and official asset holdings in a non-dollarized economy. Under appropriate restrictions on parameter values-if world variables, risk premia, and domestic policy instruments are stationary-domestic endogenous variables converge to well defined, endogenously determined steady-state levels. Equations for aggregate per capita variables can then be safely log-linearized around the steady state. ${ }^{24}$

\footnotetext{
${ }^{23}$ To convert output of the representative home good into units of consumption, $Y^{i}$ must be multiplied by the relative price $\frac{p(i)}{P}$. Hence, $Y_{t}=\frac{p_{t}(i)}{P_{t}} \frac{a Y_{t}^{i}}{N_{t}}$.

${ }^{24}$ The log-linear version of the model is in Appendix B.
} 


\section{A Dollarized Economy}

When the dollar is the only legal tender currency in circulation, there is no longer an exchange rate. All domestic prices and nominal quantities are measured in dollars, and the domestic price level is automatically equal to the foreign one. There is no accumulation of reserves, nor supply of domestic balances. Agents hold only dollar balances, and demand for dollars is determined by:

$$
\frac{M_{t}^{\$ v}}{P_{t}^{*}}=\left(\frac{\chi^{\$}}{\rho}\right)^{\sigma} C_{t}^{v}\left(\frac{1+i_{t+1}^{\$}}{i_{t+1}^{\$}}\right)^{\sigma}\left(\frac{1-\rho}{\rho W_{t} / P_{t}}\right)^{(1-\rho)(1-\sigma)}
$$

Domestic agents issue only bonds denominated in dollars. The currency premium $\left(p_{t+1}^{\$}\right)$ disappears from all equations. We assume that adoption of the dollar does not affect the steady-state level of the country premium $\left(p_{t+1}^{H}\right)$. However, dollarization may affect the short-run dynamics of the latter in so far as the currency premium enters the estimated equation that determines these dynamics prior to adoption of the dollar. In equilibrium, the interest rate on domestic bonds is determined by equation (13). Real interest rates are such that:

$$
1+r_{t+1}=\frac{1+r_{t+1}^{*}}{p_{t+1}^{H}}
$$

with $1+r_{t+1}=\frac{1+i_{t+1}^{\$}}{1+\pi_{t+1}^{C P I *}}$.

Absence of arbitrage opportunities between bonds and shares requires:

$$
1+i_{t+1}^{\$}=\frac{D_{t+1}^{i}+V_{t+1}^{i}}{V_{t}^{i}}
$$

The only relevant domestic interest rate for consumers and firms' decisions is now $i_{t+1}^{\$}$.

The law of motion for the home country's aggregate per capita real net foreign assets becomes:

$$
(1+n) a s_{t+1}=\left(1+r_{t}\right) a s_{t}+Y_{t}-C_{t}-G_{t}-\frac{\phi}{2}\left(\pi_{t}^{P P I}-\bar{\pi}\right)^{2} Y_{t}
$$

The dollarized economy is characterized by the same steady-state levels of real, aggregate per capita, endogenous variables as the non-dollarized economy-except, of course, for the fact that reserves and domestic currency 
holdings are zero. The intuition is simple. In a non dollarized economy, intertemporal real decisions between $t$ and $t+1$ are governed by the risk adjusted real interest rate $p_{t+1}^{\$}\left(1+r_{t+1}\right)$. In a dollarized economy, $1+r_{t+1}$ is the relevant real interest rate. In both cases, the relevant expression must be equal to $\frac{1+r_{t+1}^{*}}{p_{t+1}^{H}}$ for all arbitrage opportunities to be exploited. Under the assumption that adoption of the dollar by the domestic economy does not alter the foreign steady-state real interest rate nor the steady-state level of the country premium, the steady-state real interest rate that matters for agents' behavior is identical regardless of whether or not the domestic currency is still in circulation. Hence, steady-state levels of real variables are not affected by adoption of the dollar. ${ }^{25}$

Adopting the dollar affects the business cycle properties of the economy in two ways. On one side, official reserves no longer contribute to the dynamics of the home country's net foreign asset holdings, as the economy no longer holds reserves to back its money supply. Because the dynamics of consumption, employment, and output are affected by those of asset holdings, this has an effect on domestic cycles. On the other side, the currency premium is eliminated, and so are the consequences of its fluctuations, though this is not the case for the country premium.

\section{The Policy Rules}

We consider only three alternative monetary regimes, the "corner solutions" that are dominating the debate on monetary rules for emerging market economies: a currency board, inflation targeting, and dollarization.

\subsection{A Currency Board}

Because we focus on Argentina in our empirical work, we take a currency board $(C B)$ to be the benchmark monetary regime. Under a currency board, the exchange rate is fixed and the supply of domestic money is tied to the stock of foreign currency reserves accumulated by the domestic monetary authority. In general, this is the central difference between a currency board

\footnotetext{
${ }^{25}$ Of course, things would be different if dollarization affected the steady-state country premium. In the absence of convincing evidence on the likely existence and direction of the effect, we maintain the zero-effect assumption and focus on the implications of dollarization for fluctuations of the economy around an unchanged steady state.
} 
and a more traditional fixed exchange rate regime: the central bank is committed to issuing money based only on its holdings of foreign assets (and not also injecting money in the system by purchasing government bonds). In our model, we have already assumed that money supply is tied to reservesequation (28). Hence, a policy rule that implements a fixed exchange rate is also consistent with a currency board.

If the domestic nominal interest rate equals the foreign interest rate adjusted for the risk premia in the deterministic steady state of the model, steady-state depreciation is zero. Using overbars to denote steady-state levels of variables, $1+\bar{i}^{H}=\frac{1+\bar{i}^{*}}{\bar{p}^{H} \bar{p}^{\S}}$ implies $\bar{e}=0 .{ }^{26}$

We use sans serif fonts to denote percentage deviations of variables from steady-state levels. Sans serif rates denote percentage deviations of gross rates. To keep depreciation at zero in all periods-including when unexpected shocks happen-the central bank cannot rely on the (log-linear) rule:

$$
\mathrm{i}_{t+1}^{H}=\mathrm{i}_{t+1}^{*}-\mathrm{p}_{t+1}^{H}-\mathrm{p}_{t+1}^{\$} .
$$

Recalling that $i_{t+1}^{H}, p_{t+1}^{H}, p_{t+1}^{\Phi}$, and $i_{t+1}^{*}$ are all determined at time $t$, it is easily seen that this rule, combined with no-arbitrage, would stabilize expected depreciation at zero $\left(\mathrm{e}_{t+1}=0\right)$, but would leave unexpected movements of the exchange rate free to happen as a consequence of shocks.

The log-linear aggregate per capita money demand growth equation and PPP (equations (51) and (56) in Appendix B) make it possible to formulate an interest rate rule that ensures that the rate of depreciation of the domestic currency is kept at its steady-state level in all periods:

$$
\begin{aligned}
\mathrm{i}_{t+1}^{H}= & -\left(\mathrm{p}_{t+1}^{\$}-\mathrm{p}_{t}^{\$}-\mathrm{i}_{t}^{H}\right) \\
& +\frac{\bar{p}^{\Phi}\left(1+\bar{i}^{H}\right)-1}{\sigma}\left[\begin{array}{c}
\pi_{t}^{C P I *}-\mathrm{g}_{t}^{M}+\mathrm{C}_{t}-\mathrm{C}_{t-1} \\
-(1-\rho)(1-\sigma)\left(\mathrm{w}_{t}-\mathrm{w}_{t-1}\right)
\end{array}\right],
\end{aligned}
$$

where $\mathrm{g}_{t}^{M}$ is the percentage deviation of gross nominal money growth from the steady state and, from now on, $\pi_{t}^{C P I *}$ denotes the percentage deviation of gross foreign CPI inflation. Combining this equation with money demand and PPP yields $\mathrm{e}_{t}=0$, i.e., the deviation of the depreciation rate from its

\footnotetext{
${ }^{26}$ Note that the level at which the exchange rate is fixed in steady state is not determined just by setting $\bar{i}^{H}$ equal to $\frac{1+\bar{i}^{*}}{\bar{p}^{H} \bar{p}^{\S}}-1$. $\bar{\varepsilon}$ is determined by the interplay of money demand, money supply, and PPP. However, the value of the steady-state exchange rate is not central to our analysis.
} 
(zero) steady-state level must be zero in all periods. ${ }^{27}$ Because it must be $\mathrm{g}_{t}^{M}=\mathrm{g}_{t}^{M S} \forall t$ in equilibrium, and money supply is tied to foreign reserves in our model, rule (30) implements a currency board regime.

The dynamics of the risk premia affect the central bank's interest setting by generating changes in the interest rate that is consistent with the fixed exchange rate requirement. Because rule (30) implies $\mathrm{e}_{t}=0 \forall t, \mathrm{i}_{t+1}^{H}=\mathrm{i}_{t+1}^{*}-$ $\mathrm{p}_{t+1}^{H}-\mathrm{p}_{t+1}^{\$} \forall t$ follows endogenously as a characteristic of the fixed exchange rate equilibrium.

\subsection{Inflation Targeting}

We consider two alternative specifications for the inflation targeting regime: strict inflation targeting (SIT) and flexible inflation targeting $(F I T)$.

Under strict inflation targeting, the central bank keeps inflation constant at its steady-state level in all periods (including those in which unexpected shocks happen): $\pi_{t}^{C P I}=0$-where $\pi^{C P I}$ from now on denotes the percentage deviation of gross CPI inflation from the steady state. ${ }^{28}$ An operational rule that implements this goal can be obtained from the (log-linear) money demand growth equation (51) in Appendix B. Setting the domestic interest rate so that

$$
\begin{aligned}
\mathrm{i}_{t+1}^{H}= & -\left(\mathrm{p}_{t+1}^{\$}-\mathrm{p}_{t}^{\$}-\mathrm{i}_{t}^{H}\right) \\
& +\frac{\bar{p}^{\$}\left(1+\bar{i}^{H}\right)-1}{\sigma}\left[\begin{array}{c}
\pi_{t}^{C P I}-\mathrm{g}_{t}^{M}+\mathrm{C}_{t}-\mathrm{C}_{t-1} \\
-(1-\rho)(1-\sigma)\left(\mathrm{w}_{t}-\mathrm{w}_{t-1}\right)
\end{array}\right]
\end{aligned}
$$

makes it possible to achieve the target. To implement strict inflation targeting, the interest rate chosen by the policymaker at time $t$ must react to the current and past movements of the risk premium in order to offset their impact on money demand.

If foreign inflation is constant, strict inflation targeting and a currency board are exactly equivalent in our model. Because PPP holds, if foreign inflation is constant, it is $\pi_{t}^{C P I}=\mathrm{e}_{t}$. In this case, a regime that implements $\pi_{t}^{C P I}=0$ is exactly equivalent to a regime that implements $\mathrm{e}_{t}=0$ in terms of business cycle properties.

\footnotetext{
${ }^{27}$ In log-linear equations, $\pi$ denotes the percentage deviation of the gross inflation rate from its steady-state level.

${ }^{28}$ This is the interpretation of inflation targeting in SGU.
} 
We interpret flexible inflation targeting as a Taylor rule of the form:

$$
\mathrm{i}_{t+1}^{H}=\alpha \pi_{t}^{C P I}+.5 \mathrm{Y}_{t},
$$

where $\alpha$ can be significantly above the Taylor-level of 1.5, consistent with the central bank paying closer attention to inflation than to GDP. (The higher $\alpha$, the faster inflation returns to the steady state following a shock. $)^{29}$

\subsection{Dollarization}

As observed above, when the home economy is officially dollarized, there is no longer an interest rate on domestic currency bonds that the home monetary authority can maneuver. Arbitrage across domestic and foreign dollar bonds by foreign households ties $i^{\$}$ to $i^{*}$ :

$$
\mathrm{i}_{t}^{\$}=\mathrm{i}_{t}^{*}-\mathrm{p}_{t}^{H} .
$$

$i^{\$}$ simply follows the dynamics of foreign monetary policy, adjusted for country risk, which is not removed by dollarization $(D O L)$.

\section{The Foreign Economy and Risk Premia}

In this section, we present the empirical models of the foreign economy and Argentine risk premia that we use in the rest of the paper. The foreign economy is identified with the United States, because this is the country with which Argentina has the strongest financial ties. ${ }^{30}$ We use monthly data over the period 1994:4-1999:12.

We assume that risk premia are determined in international bond markets. We measure $\mathrm{p}_{t+1}^{\$}$ and $\mathrm{p}_{t+1}^{H}$ with two bond yield differentials: the spread (stripped of collateral) of the Argentine Brady bond over a comparable U.S. Treasury bond and the spread of a peso denominated Argentine government

\footnotetext{
${ }^{29}$ Our version of flexible inflation targeting (based on an instrument rule) differs from that popularized by Svensson (based on a targeting rule). See Svensson (2001) and references therein.

${ }^{30}$ Argentina has also strong trade linkages with Europe, to the point that some scholars have argued that "euroization" may be more beneficial than dollarization (Frankel and Rose, 2000). Recent changes in the Argentine currency board may reflect in part these considerations. See Oppers (2000) for an analysis of the advantages of dual currency boards.
} 
bond over a comparable Argentine dollar bond, respectively. We assume that the expected depreciation rate $\left(e_{t+1}\right)$ is zero under a currency board, so that $\mathrm{p}_{t+1}^{\$}$ may be thought of as measuring the risk of a sudden abandonment of the currency board regime.

In addition to premia, only three foreign variables affect the home economy directly in the theoretical model: world GDP $\left(\mathrm{Y}_{t}^{W}\right)$, interest rate $\left(i_{t+1}^{*}\right)$, and consumer price inflation $\left(\pi_{t}^{C P I *}\right)$. The negligible impact of home GDP on world aggregates allows us to identify $Y_{t}^{W}$ with $Y_{t}^{*}$. As we use monthly data, we proxy U.S. GDP per capita with an index of industrial production divided by the labor force. We use the Federal Funds Rate as the relevant short-term nominal interest rate. The 12-month change in the consumer price index measures $\pi_{t}^{C P I *}$ for consistency with the Federal Funds Rate, which is measured on annual basis. ${ }^{31}$

We follow a general-to-specific empirical modeling strategy (Hendry, 1995), starting from the estimation of a stationary, unrestricted, reduced form VAR system for $\left[\pi_{t}^{C P I *}, \mathrm{Y}_{t}^{W}, \mathrm{i}_{t+1}^{*}, \mathrm{p}_{t+1}^{\$}, \mathrm{p}_{t+1}^{H}\right]^{\prime}$, in which each equation includes a constant, six lags of every endogenous variables, and four impulse dummies (two for the Mexican crisis and two for the Russian default) to obtain white noise residuals. We check stationarity at system level by testing the null hypothesis that the VAR system has full rank. Standard test statistics for the determination of the lag length suggest that a common lag length of three is appropriate for this VAR. ${ }^{32}$

The small open economy assumption is not fully supported by the data over the sample period we consider. The assumption that U.S. variables are strongly exogenous may or may not be rejected when tested in the unrestricted VAR for $\left[\pi_{t}^{C P I *}, \mathrm{Y}_{t}^{W}, \mathrm{i}_{t+1}^{*}, \mathrm{p}_{t+1}^{\$}, \mathrm{p}_{t+1}^{H}\right]^{\prime}$, depending on the particular specification. This is mainly due to a statistically significant, but small and short-lived, effect of the risk premia in the equation for $i_{t+1}^{*}$ and a nonnegligible correlation between the respective reduced form residuals, even after controlling for the Mexican and the Russian crises. The idea that developments in Argentine risk premia might affect other emerging markets via international spillovers, and hence global liquidity conditions and Federal Reserve policy, is intriguing. Nonetheless, at this stage, the evidence is not sufficiently strong to justify abandoning the small open economy assump-

\footnotetext{
${ }^{31}$ All variables are in percentage deviations from trend. See Appendix D for details on data sources, transformations, and detrending procedures.

${ }^{32}$ All results that are not reported here are available on request.
} 
tion. ${ }^{33}$ Consistent with this assumption, we estimate two blocks of equations separately, for $\left[\pi_{t}^{C P I *}, \mathrm{Y}_{t}^{W},{ }_{t+1}^{*}\right]^{\prime}$ and $\left[\mathrm{p}_{t+1}^{\$}, \mathrm{p}_{t+1}^{H}\right]^{\prime}$, respectively, with contemporaneous and lagged U.S. variables entering the premia equations as exogenous regressors (with the same number of lags), but no effect of the premia on the U.S. economy. Three lags remain appropriate for both blocs.

\subsection{The Foreign Economy}

U.S. consumer price inflation has been remarkably stable in the second part of the 1990s. In addition, $\pi_{t}^{C P I *}$ does not predict nor is predicted by lags of $\mathrm{Y}_{t}^{*}$ and $\mathrm{i}_{t+1}^{*}$ in a VAR for $\left[\pi_{t}^{C P I *}, \mathrm{Y}_{t}^{W}, \mathrm{i}_{t+1}^{*}\right]^{\prime}$, orthogonalized with a triangular decomposition of the variance-covariance matrix of the reduced form residuals with the order shown. Moreover, consumer price inflation has been stable also in Argentina in the second part of the 1990s. As a result, the inflation differential between the two countries is not significant in the premia equations (see below). Hence, we consider only $\mathrm{y}_{t}^{W}$ and $\mathrm{i}_{t+1}^{*}$ in the VAR for the U.S. economy, set U.S. inflation equal to its sample average in the simulations below, and do not include the inflation differential as exogenous variable in the VAR for the premia. To mitigate a strong positive effect of the first lag of $i_{t+1}^{*}$ on $Y_{t}^{W}$, the final specification of the VAR for $\left[Y_{t}^{W}, i_{t+1}^{*}\right]^{\prime}$ includes also an index of international commodity prices, entered as an exogenous variable with the same number of lags.

Table 1 reports the estimated reduced form equations of this VAR together with a battery of diagnostic tests, the correlation matrix of the reduced form residuals, and their adjusted R-squared. ${ }^{34}$ The data do not reject the specification and the fit is good.

Following Rotemberg and Woodford (1997), the reduced form residuals are orthogonalized by using a triangular decomposition of their variancecovariance matrix placing $Y_{t}^{W}$ first in the causal ordering. Thus, we assume that innovations to $i_{t+1}^{*}$ affect $Y_{t}^{W}$ with at least one lag, while we allow $i_{t+1}^{*}$ to respond contemporaneously to innovations to $Y_{t}^{W}$. Therefore, we interpret shocks to $i_{t+1}^{*}$ as exogenous shocks to monetary policy in the U.S. and shocks

\footnotetext{
${ }^{33} \mathrm{~A}$ previous version of this paper analyzes the implications of departing from the small open economy assumption along these lines and is available at http://www2.bc.edu/ ghironi/research.html.

${ }^{34}$ In Table $1, \mathrm{Y}_{t}^{W}$ and $\mathrm{i}_{t+1}^{*}$ are labelled $Y F$ and $I F$, respectively; the commodity price index is labelled $C O M P$.
} 
to $Y_{t}^{W}$ as world output shocks. The estimated variances of the orthogonalized innovations (used in the simulation below) and the matrix governing the contemporaneous relations between $Y_{t}^{W}$ and $i_{t+1}^{*}$ (i.e., the triangular factor) are reported at the bottom of Table 1 .

Since the triangularization identifies the VAR exactly, the structural form equations (not reported) are easily obtained by premultiplying the reduced form by the triangular factor. ${ }^{35}$ To keep the simulated model as simple as possible, we drop the coefficients that are not statistically significant in the reduced form and the contemporaneous effect of $Y_{t}^{W}$ on $i_{t+1}^{*}$ (which is also not statistically significant) from the equations that we combine with the theoretical model of the home economy. To avoid introducing a "pricepuzzle' (which is not fully resolved by the commodity price variable) in the simulation, we exclude also the first lag of $\mathrm{i}_{t+1}^{*}$ from the equation for $\mathrm{Y}_{t}^{W}$, even though it is significant in the reduced form. ${ }^{36}$ Thus, the equations that actually enter the simulation are:

$$
\begin{gathered}
\mathrm{Y}_{t}^{W}=.67 \mathrm{Y}_{t-1}^{W}+\mathrm{u}_{t}^{\mathrm{y}^{W}} \\
\mathrm{i}_{t+1}^{*}=.09 \mathrm{Y}_{t-1}^{W}+.97 \mathrm{i}_{t}^{*}+\mathrm{u}_{t}^{\mathrm{i}^{*}} .
\end{gathered}
$$

U.S. output is described by an $A R(1)$ process, while U.S. monetary policy is represented by a very simple, backward-looking, Taylor-type rule with strong interest rate smoothing.

\footnotetext{
${ }^{35}$ Ignoring the constant and higher order lags, suppose that the structural form of the VAR is:

$$
A_{0} \mathrm{Y}_{t}=A_{0} A_{1} \mathrm{Y}_{t-1}+A_{0} C_{0} \mathrm{X}_{t}+A_{0} C_{1} \mathrm{X}_{t-1}+\mathrm{u}_{t}, \quad t=1, \cdots T
$$

where $\mathrm{Y}_{t}, \mathrm{X}_{t}$ denote vectors of endogenous and exogenous variables, respectively; $\mathrm{u}_{t}$ is a vector of orthogonal innovations with variance matrix $\Omega$ such that $A_{0}^{-1} \mathrm{u}_{t}=\epsilon_{t} ; \epsilon_{t}$ is the vector of the reduced form residuals, with variance-covariance matrix $\Sigma$. Given an estimate of $A_{1}, C_{0}, C_{1}$, and $\Sigma, A_{0}$ and $\Omega$ are easily obtained from $A_{0}^{-1} \Omega A_{0}^{-1^{\prime}}=\Sigma$, and other structural parameters are obtained as described in the text.

${ }^{36}$ It should be noted, though, that the cumulative impact of $i_{t+1}^{*}$ on $Y_{t}^{W}$ is close to zero in the structural form, and the first lag of $i_{t+1}^{*}$ is not strongly statistically significant in the reduced form equation for $\mathrm{Y}_{t}^{W}$. The cumulative effect of $\mathrm{Y}_{t}^{W}$ on $\mathrm{i}_{t+1}^{*}$, instead, is clearly positive in the structural form and estimated much more precisely in the reduced form. If we include a fourth lag in the system, the cumulative impact of $i_{t+1}^{*}$ on $Y_{t}^{W}$ becomes slightly negative. The fourth lag, however, is not significant at system level.
} 


\subsection{The Risk Premia}

In the theoretical model, $\mathrm{p}_{t+1}^{\$}$ and $\mathrm{p}_{t+1}^{H}$ are taken as given without imposing any a-priori restrictions on their interdependence or their relation with foreign and domestic variables. We model $\mathrm{p}_{t+1}^{\$}$ and $\mathrm{p}_{t+1}^{H}$ empirically with a simple VAR including three lags of both foreign and domestic variables as exogenous regressors.

The VAR for $\left[\mathrm{p}_{t+1}^{\$}, \mathrm{p}_{t+1}^{H}\right]^{\prime}$ includes $\mathrm{Y}_{t}^{W}$ and $\mathrm{i}_{t+1}^{*}$ to capture the impact of external real and monetary shocks and a proxy of the private sector's net foreign assets to GDP ratio $\left(\mathrm{as}_{t}-\mathrm{Y}_{t}\right)$ to allow for a feedback from domestic fundamentals to premia. ${ }^{37}$ As mentioned above, the CPI inflation differential between the U.S. and Argentina $\left(\pi_{t}^{C P I}-\pi_{t}^{C P I *}\right)$ is not statistically significant in a VAR for $\left[\mathrm{p}_{t+1}^{\$}, \mathrm{p}_{t+1}^{H}, \mathrm{as}_{t}-\mathrm{Y}_{t}, \pi_{t}^{C P I}-\pi_{t}^{C P I *}\right]^{\prime}$ and is not included in the final specification.

Table 2 reports the estimated reduced form equations of this VAR together with a battery of diagnostic tests, the correlation matrix of the reduced form residuals, and their adjusted R-squared. ${ }^{38}$ The overall performance of this VAR is also relatively good: it fits the data well and there is no evidence of mispecification, except for the sign of some serial correlations of order higher than six (the maximum number of lags that can be estimated with the available sample), especially in the equation for $\mathrm{p}_{t+1}^{\$} \cdot{ }^{39}$

Both domestic and international variables affect the currency and country premia according to the estimated (reduced form) equations. Lagged and contemporaneous values of both $a s_{t}-Y_{t}$ and $i_{t+1}^{*}$ enter with statistically significant coefficients and plausible signs. The cumulative impact of $\mathrm{i}_{t+1}^{*}$ on the currency premium is particularly large. Not surprisingly, currency and country premia appear also closely interrelated. The contemporaneous correlation of the residuals is positive and large, as well as the lagged impact of the country premium on the currency premium. Interestingly, lagged values of the currency premium have a small, negative- "dampening"-effect on the country premium. ${ }^{40}$

\footnotetext{
${ }^{37}$ As a proxy for $\mathrm{as}_{t}-\mathrm{Y}_{t}$, we use a monthly measure of the ratio of total net foreign assets to GDP constructed by interpolating quarterly data. (See Appendix D for details.)

${ }^{38} \mathrm{In}$ Table $2, \mathrm{p}_{t}^{H}, \mathrm{p}_{t}^{\$}$, and $\mathrm{as}_{t}-\mathrm{Y}_{t}$ are denoted $P \$, P H$, and $N F A$, respectively. Note that an increase in $P \$$ and $P H$ means a reduction in the risk premia (i.e., an improvement).

${ }^{39}$ In this equation, the null hypothesis of absence of autocorrelation is rejected with 99 percent confidence; in the equation for $\mathrm{p}_{t+1}^{H}$ the evidence of autocorrelation is weaker.

${ }^{40}$ This effect becomes clearly significant if we estimate the system with four lags.
} 
The interpretation of the contemporaneous correlation between the two spreads we use to measure premia is controversial. ${ }^{41}$ The no-arbitrage conditions (12)-(14) do not impose any restriction on this moment of the data. Thus, they do not suggest any particular direction of causation. We remain agnostic on this issue and assume that the underlying sources of disturbances to currency and country premia are uncorrelated and have a symmetric impact on the two spreads we consider. More precisely, we assume that the dynamic interdependence of $\mathrm{p}_{t+1}^{\$}$ and $\mathrm{p}_{t+1}^{H}$ is driven by two orthogonal innovations: a shock to country risk and a shock to currency risk that we denote $\mathbf{u}_{t}^{\mathrm{p}^{\mathrm{S}}}$ and $\mathbf{u}_{t}^{\mathrm{p}^{H}}$ respectively. We further assume that the contemporaneous impact of $\mathrm{p}_{t+1}^{H}$ on $\mathrm{p}_{t+1}^{\Phi}$ is the same as the impact of $\mathrm{p}_{t+1}^{\$}$ on $\mathrm{p}_{t+1}^{H}$. This assumption and the hypothesis that $\mathbf{u}_{t}^{\mathbf{p}^{\mathbb{S}}}$ and $\mathbf{u}_{t}^{\mathrm{p}^{H}}$ are uncorrelated are sufficient to identify the VAR for $\left[\mathrm{p}_{t}^{\$}, \mathrm{p}_{t}^{H}\right]^{\prime}$ exactly (see Giannini, 1992, p. 101).

The estimated matrix of the contemporaneous effects is reported at the bottom of Table 2, together with the variance matrix of the orthogonal shocks (used in the simulation below). As expected, the contemporaneous interdependence is positive and sizable (and estimated very precisely). As in the case of the VAR for the U.S. economy, since the model is exactly identified, the structural form equations (not reported) are easily obtained by premultiplying the reduced form by the estimated matrix of the contemporaneous effects.

The equations that are actually used in the simulation below are the following:

$\mathrm{p}_{t+1}^{\$}=.27 \mathrm{p}_{t+1}^{H}+.01 \mathrm{p}_{t}^{\$}+.43 \mathrm{p}_{t}^{H}-3 \mathrm{i}_{t+1}^{*}+.4\left(\mathrm{as}_{t-2}-\mathrm{Y}_{t-2}\right)+\mathrm{u}_{t}^{\mathrm{p}^{\S}}$

$\mathrm{p}_{t+1}^{H}=.27 \mathrm{p}_{t+1}^{\$}-.08 \mathrm{p}_{t}^{\$}+.29 \mathrm{p}_{t}^{H}-.5 \mathrm{i}_{t+1}^{*}+.4\left(\mathrm{as}_{t}-\mathrm{Y}_{t}\right)+.3\left(\mathrm{as}_{t-1}-\mathrm{Y}_{t-1}\right)+\mathrm{u}_{t}^{\mathrm{p}^{H}}$.

The empirical model of the premia that we combine with the theoretical model of the home economy is a structural VAR of order 1 augmented by the foreign interest rate and the domestic net-foreign-assets-to-GDP ratio. We obtain these equations by dropping the coefficients that are not statistically significant in the reduced form from the structural form, and making two ad hoc adjustments to keep the complete model as simple as possible.

First, we include only the first lag of $\mathrm{p}_{t+1}^{\$}$ and $\mathrm{p}_{t+1}^{H}$ in the system. Thus, somewhat arbitrarily in light of the $t$-statistics of the reduced form equations,

\footnotetext{
${ }^{41}$ See Neumeyer and Nicolini (2000) and Borensztein and Berg (2000) for a discussion with reference also to Argentina.
} 
we exclude the term $-.26 \mathrm{p}_{t-2}^{\$}+.16 \mathrm{p}_{t-2}^{H}$ from the structural equation for $\mathrm{p}_{t+1}^{\$}$ (including instead .01 $\mathrm{p}_{t}^{\$}$ ) and the term -.35 $\mathrm{p}_{t-1}^{H}+.36 \mathrm{p}_{t-2}^{H}$ from the equation for $\mathrm{p}_{t+1}^{H}$, (including instead $-.08 \mathrm{p}_{t}^{\$}$, a small dampening effect). This adjustment does not alter either the short- or the long-run dynamic interaction of $\mathrm{p}_{t+1}^{\$}$ and $\mathrm{p}_{t+1}^{H}$ substantially given the estimated sign and magnitude of the involved coefficients, but it implies slightly less persistence and a smoother path following shocks to the premia. ${ }^{42}$ At the same time, the adjustment simplifies the simulated system significantly, thereby enhancing the precision of the numerical solution and the robustness of our conclusions.

Second, we include only the contemporaneous effects of $i_{t+1}^{*}$ on $p_{t+1}^{\$}$ and $\mathrm{p}_{t+1}^{H}$ rather than the contemporaneous impact and the third lag of $\mathrm{i}_{t+1}^{*}$ in the equation for $\mathrm{p}_{t+1}^{\$}$ and the second and the third lag of $\mathrm{i}_{t+1}^{*}$ in $\mathrm{p}_{t+1}^{H}$. These contemporaneous effects are very close to the unrestricted cumulative impacts of $\mathrm{i}_{t+1}^{*}$ on $\mathrm{p}_{t+1}^{\$}$ and $\mathrm{p}_{t+1}^{H}$ in the structural equations, which are -3.3 and -.5 , respectively. Therefore, this second adjustment too leaves the dynamic interaction of $\mathrm{p}_{t+1}^{\$}$ and $\mathrm{p}_{t+1}^{H}$ basically unchanged: it shortens the transmission mechanism of the total short-run impact of U.S. monetary policy on the premia, leaving its magnitude unaffected.

\section{Calibration and Evaluation}

\subsection{Calibration and Solution Procedure}

To generate a complete model of the world economy, we combine the empirical model of the risk premia and the foreign economy with the log-linear theoretical equations for the home economy and the relevant domestic interest setting rule. We solve this model using the method illustrated by Uhlig (1999).

We calculate the steady-state levels of foreign variables and risk premia as averages of the respective trend components over the sample period (on a monthly basis). It is $\bar{p}^{H}=.9938$ and $\bar{p}^{\$}=.9974$. The steady-state nominal interest rate $\left(\bar{i}^{*}\right)$ is .00399. Steady-state CPI inflation $\left(\bar{\pi}^{C P I *}\right)$ is .0022 .

\footnotetext{
${ }^{42}$ The terms $-.35 \mathrm{p}_{t-1}^{H}$ and $.36 \mathrm{p}_{t-2}^{H}$ roughly cancel out in the equation for $\mathrm{p}_{t+1}^{H}$. The term $.16 \mathrm{p}_{t-2}^{H}$ would tend to exacerbate the strong positive effect of $\mathrm{p}_{t+1}^{H}$ on $\mathrm{p}_{t+1}^{\$}$, but the term $-.25 \mathrm{p}_{t-2}^{\$}$ would tend to dampen this effect. The effect of $.01 \mathrm{p}_{t}^{\$}$ is negligible given the size of its coefficient, while a small dampening effect via the term $-.08 \mathrm{p}_{t}^{\$}$ is a constant feature of the data across different specifications.
} 
Foreign aggregate per capita real GDP $\left(\bar{Y}^{W}\right)$ is set to 2400.

We choose parameter values to generate steady-state levels of endogenous variables that match basic features of the Argentine economy when combined with steady-state premia and foreign variables. We use the following parameter values: $n=.0011$ (average monthly growth rate of Argentine population over our sample), $\beta=.9936, \sigma=.1$ (consistent with strongly risk averse households), $\rho=.45, \omega=1.2, \theta=3.6, \phi=200$ (raising output price inflation to 1.1 percent starting from a steady state value of 1 percent requires firms to purchase materials in an amount equal to .01 percent of their revenues), $\chi=\chi^{\$}=.001$ (so that real balances have a negligible direct impact on welfare). Finally, we assume $\nu=1$, i.e., the lag in the production-to-sale process in the domestic economy lasts only one period.

The implied steady-state levels of endogenous variables are as follows: $r=.0107$ (.008 under dollarization), $\bar{L}=.37$ (agents spend a little more than one-third of each period working), $\bar{w}=1076, \bar{Y}=556$ (implying that $\left.\frac{\bar{w} \bar{L}}{\bar{Y}} \approx .72\right), \bar{d}=157$ (implying $\frac{\bar{d}}{\bar{Y}} \approx .28$, so that the income distribution identity $\frac{\bar{w} \bar{L}}{\bar{Y}}+\frac{\bar{d}}{\bar{Y}}=1$ holds), $\bar{C}=555$ (thus $\frac{\bar{C}}{\bar{Y}} \approx .998$, implying a very low saving rate), $\overline{a s c}=22,474, \bar{v}=22,643$ (the equity value of the Argentine economy is very high because it is the present discounted value of profits over the infinite future, and the rate at which profits are discounted $-r$-is low), $\overline{a s}=-169$ (households' assets $-\overline{a s c}-$ are positive and large because of the large equity value of Argentina in the model; the net foreign debt is approximately 30 percent of GDP, as $\left.\frac{|\overline{a s}|}{\bar{Y}} \approx .30\right), \bar{m}=16.61, \overline{r e s}=16.59$ (reserves are a small fraction of GDP- $\frac{\bar{m}}{\bar{Y}} \approx .03$-because a small value of $\chi$ implies a small demand of pesos; we discuss the consequences of higher values of $\chi$ below).

The economy is subject to six uncorrelated, zero-mean shocks. The variances of the shocks to premia, foreign monetary policy, and foreign GDP are given by the variances of the orthogonal residuals of the two VAR models in tables 1 and 2. In addition to these four shocks, the deviation of home per capita GDP from the steady state is subject to a zero-mean productivity shock (Z), with an estimated standard deviation of approximately 1.018 (the standard deviation of the residuals of an $A R(1)$ process for $\mathrm{Y}$ ). The percentage deviation of government consumption from the steady state $(\mathrm{G})$ is also assumed to follow an $A R(1)$ process with estimated coefficient .81 and residuals standard deviation equal to 1.605. We assume that domestic productivity and government spending shocks are uncorrelated and not 
correlated with the other exogenous disturbances.

As far as the monetary rules are concerned, we capture the consequences of dollarization on risk premia by setting $\bar{p}^{\S}=1$, dropping the equation for $\mathrm{p}_{t+1}^{\$}$ from the system, assuming $\mathbf{p}_{t+1}^{\$}=0 \forall t$ in the remaining equations, and modifying the variance-covariance matrix of the shocks accordingly. ${ }^{43}$

When analyzing flexible inflation targeting, we consider two alternative values of $\alpha$, the parameter that measures the intensity of the central bank's reaction to inflation in this regime, $\alpha=5$ and $\alpha=10$. Finally, as we have set U.S. inflation constant at the steady state, the business cycle and welfare properties of a currency board are the same as those of strict inflation targeting in our framework.

Simulated moments are based on 1000 replications. For each run, series of length equal to 1260 months (105 years) are generated and moments are computed based on the last five years of data (the last 60 months), discarding the first 1200 to work with ergodic distributions.

\subsection{Evaluation}

To evaluate the empirical performance of the framework, we compare the second moments predicted by the model under the currency board regime $(C B)$ to those implied by Argentine data over the period 1995:3-1999:12. ${ }^{44}$

\footnotetext{
${ }^{43}$ Note that our measures of $\mathrm{p}^{H}$ and $\mathrm{p}^{\$}$ capture total country and currency risk, respectively and are functions of the marginal probability of a currency or a country "crisis," respectively. By setting $\mathrm{p}^{\$}=0$, we are implicitly assuming that the unconditional probability of abandoning dollarization is zero, or that the probability of a currency change conditional on both the absence and the presence of a "country crisis" is zero.A weaker assumption could be made by interpreting the unobservable variables $\mathbf{u}_{t}^{\mathrm{p}^{8}}$ and $\mathbf{u}_{t}^{\mathrm{p}^{H}}$, defined by the identifying restrictions discussed in the previous section, as a shock to pure currency and country risk, respectively, as opposed to shocks to total risk of these events measured by the observable reduced form residuals. Under such interpretation, the impact of setting $\mathbf{u}_{t}^{\mathbf{p}^{\mathbb{8}}}$ to zero on both $\mathrm{p}_{t+1}^{\$}$ and $\mathrm{p}_{t+1}^{H}$ could be easily quantified, and a VAR for the new series re-estimated. The hypothesis that $\mathrm{p}_{t+1}^{\$}=0 \forall t$ is stronger, but it is independent from identification assumptions. Both strategies, however, are potentially subject to the Lucas critique. (See SGU for an argument against the full credibility of dollarization.)

${ }^{44}$ The choice of a slightly shorter sample period than that used in estimation is due to the lack of consistent data for domestic GDP and consumption. Because we can explain our welfare results clearly by referring to the second-moment properties of the model, we omit the presentation of impulse responses. Impulse responses to all disturbances we consider are stationary and well-behaved and display a reasonable degree of persistence. Diagrams are available on request.
} 
Table 3 reports the standard deviations and the correlation matrix of home GDP $\left(\mathrm{Y}_{t}\right)$, foreign GDP $\left(\mathrm{Y}_{t}^{W}\right)$ and interest rate $\left(\mathrm{i}_{t+1}^{*}\right)$, currency and country premia $\left(\mathrm{p}_{t+1}^{\$}\right.$ and $\left.\mathrm{p}_{t+1}^{H}\right)$, employment $\left(\mathrm{L}_{t}\right)$, consumption $\left(\mathrm{C}_{t}\right)$, and the relative price $\left(\mathrm{RP}_{t}\right.$, where $\left.R P_{t} \equiv \frac{p_{t}(i)}{P_{t}}\right)$, respectively, in percentage deviations from trend. Table 4 reports autocorrelations of home GDP as well as the correlation of all other variables with the latter up to the fifth lag and lead. Both tables include results for $\chi=1$ along with those for the benchmark parameterization, in which $\chi=.001$.

Our framework matches the standard deviations of employment and consumption quite well (Table 3). The implied volatility of consumption is only slightly higher than in the data, while employment volatility is only slightly lower. The volatility of home GDP and the relative price are clearly underpredicted. In equilibrium, domestic GDP is driven by the relative price and world GDP. PPP combined with constant foreign inflation, zero depreciation, and the absence of terms of trade shocks is a likely explanation for the underprediction of relative price volatility. In addition, estimated U.S. GDP volatility is relatively small over the sample we consider. Small relative price and U.S. GDP volatility combine to yield an underprediction of Argentine GDP volatility.

The model overpredicts the volatility of risk premia. This is mainly because the predicted volatility of the private sector's net-foreign-assets-toGDP ratio (not reported) is higher than in the data. In the model, agents use changes in asset holdings to smooth consumption dynamics to a more significant extent than in the data, in the sense that the model underpredicts the consumption-GDP correlation. More volatile assets translate into more volatile risk premia. However, this result depends also on the value of $\chi$. Raising $\chi$ from its low level in the benchmark parameterization lowers asset volatility through the impact of steady-state foreign reserves on the dynamics of domestic assets in the log-linear version of equation (29). Higher values of $\chi$ can thus improve the matching of risk premia volatility. (A higher $\chi$ generates also an even better match for the standard deviation of consumption, but it worsens the match for employment, GDP, and the relative price.)

Our framework matches also all signs and many magnitudes of the correlations between key macro variables, except those of the relative price and that between the country premium and the foreign interest rate (perhaps because of the adjustments we made in the premia equations). The framework matches the correlation between employment and consumption, and 
the correlations of these two variables with the others, particularly well. As mentioned above, the apparatus underpredicts the correlation between consumption and home GDP. This is probably because imperfections in domestic financial markets not featured in our model are at work in Argentina, forcing consumption to track current income closely. The framework underpredicts also the magnitude of the correlation between home GDP and the premia and overpredicts that with foreign GDP and interest rate.

The evidence on the serial correlations with domestic GDP in Table 4 suggests that, in general, our framework generates less persistence than in the data. This can be due to the simplifying adjustments in the empirical model of the premia, or to the fact that we have introduced only a one-month lag in the production-to-sale process, or a combination of both. Lead correlations are also matched poorly. Nonetheless, the simulated moments track the dynamic comovements of employment and, to a lesser extent, consumption with home GDP quite well. The matching of the comovement between foreign and home GDP is also reasonably good.

In sum, the overall performance of the framework is relatively good. It can match the sign and magnitude of many moments of the data closely, including most contemporaneous correlations, the volatility, and, to a lesser extent, persistence of employment and consumption-the two variables whose second moments enter the welfare analysis of alternative monetary regimes. Moreover, our framework provides plausible explanations for most features of the data which are replicated in a less than fully satisfactory manner.

\section{Welfare Analysis}

The estimates of the unconditional second moments of consumption and the labor effort under alternative regimes can be used to evaluate the performance of the regimes in terms of aggregate welfare.

\subsection{The Welfare Criterion}

A measure of welfare that takes fully into account the implications of Jensen's inequality can be obtained as follows.

Under the assumption that the weight attached to real balances in con-

sumers' utility - $\chi, \chi^{\$}$ - is sufficiently small that the volatility of real money 
holdings has negligible (direct) effects on welfare regardless of the monetary regime, the expected period utility in aggregate per capita terms is:

$$
E[u(C, L E)]=E\left[\frac{\left(C^{\rho} L E^{1-\rho}\right)^{1-\frac{1}{\sigma}}}{1-\frac{1}{\sigma}}\right],
$$

where $E(\cdot)$ is the unconditional expectation operator, $C$ is aggregate per capita consumption, and $L E$ is aggregate per capita leisure. ${ }^{45} 46$

For sufficiently small deviations from the steady state, the welfare criterion (34) can be rewritten (omitting unimportant constants) as:

$$
E\left\{\frac{\exp \left[\rho\left(1-\frac{1}{\sigma}\right) \mathrm{C}-(1-\rho)\left(1-\frac{1}{\sigma}\right) \frac{\bar{L}}{1-\bar{L}} \mathrm{~L}\right]}{1-\frac{1}{\sigma}}\right\}
$$

Hence, under assumptions of normality — and continuing to neglect unimportant terms - the welfare criterion becomes:

$$
\begin{aligned}
& \frac{\left\{[E(C)]^{\rho}[E(L)]^{\left.-(1-\rho) \frac{\bar{L}}{1-\bar{L}}\right\}^{1-\frac{1}{\sigma}}}\right.}{1-\frac{1}{\sigma}} \\
& \times \exp \left\{\begin{array}{c}
-\frac{1}{2} \rho\left(1-\frac{1}{\sigma}\right)\left[1-\rho\left(1-\frac{1}{\sigma}\right)\right] \sigma_{\mathrm{C}}^{2} \\
+\frac{1}{2}(1-\rho) \frac{\bar{L}}{1-\bar{L}}\left(1-\frac{1}{\sigma}\right)\left[1+(1-\rho)\left(1-\frac{1}{\sigma}\right) \frac{\bar{L}}{1-\bar{L}}\right] \sigma_{\mathrm{L}}^{2} \\
-\rho(1-\rho)\left(1-\frac{1}{\sigma}\right)^{2} \frac{\bar{L}}{1-\bar{L}} \sigma_{\mathrm{C}, \mathrm{L}}
\end{array}\right\},
\end{aligned}
$$

\footnotetext{
${ }^{45}$ Calvo and Obstfeld (1988) show how to derive an intertemporal social welfare function in terms of aggregate consumption in a continuous time version of the model used here. A formal derivation of the discrete time counterpart can be found in Ghironi (2000). Because the choice of the monetary regime takes place from an ex ante perspective, the unconditional expectation of period social welfare is a proper choice criterion. Details of the derivation of the equations in this section are available on request.

${ }^{46}$ In principle, it is not appropriate to apply the welfare criterion of a stochastic setting to a perfect foresight model, whose linearized equations do not include variance and covariance terms. However, second moments disappear from the log-linearized equations under assumptions of homoskedasticity. In this case, the log-linear rational expectations model coincides with the rational expectation of the log-linear perfect-foresight equations, which we solve using Uhlig's (1999) methods. Moreover, to the extent that the estimated equations for $\mathrm{p}^{H}$ and $\mathrm{p}^{\$}$ capture the dynamics of the time-varying risk premia that would be generated by a rational expectations model under heteroskedasticity, the inaccuracy of our analysis would be mitigated also under the latter assumption. The good empirical performance of the framework lends support to our approach.
} 
where $\sigma_{\mathrm{C}}^{2}$ is the variance of $\mathrm{C}, \sigma_{\mathrm{L}}^{2}$ is the variance of $\mathrm{L}$, and $\sigma_{\mathrm{C}, \mathrm{L}}$ is their covariance.

The first part of the expression in (35) is not affected by the monetary rule because the unconditional expected values of consumption and the labor effort are given by the respective steady-state levels, which are invariant to the monetary regime. Instead, the monetary rule affects the second part of this expression, the exponential term. The policy rule affects welfare by causing different values for the variances of the deviations of consumption and labor from the steady state and for their covariance. Because the intertemporal elasticity of substitution $(\sigma)$ is smaller than 1 in our simulations, welfare is higher the smaller the argument of the exponential in (35).

A higher value of $\sigma_{C}^{2}$ causes the argument of the exponential to be larger. Hence, it has a negative effect on welfare. The same is true of a negative covariance between $C$ and $L$. A negative covariance between consumption and labor implies that consumption and leisure tend to move in the same direction. When agents are risk averse, their welfare is higher if consumption and leisure move in opposite directions, providing a source of risk diversification.

The effect of $\sigma_{\mathrm{L}}^{2}$ on welfare is ambiguous. More uncertainty in leisure tends to decrease welfare directly. However, it also causes $\exp [E(\mathrm{~L})]=$ $[E(L)] \exp \left(-\frac{\sigma_{\mathrm{L}}^{2}}{2}\right)$ to be smaller, which has a positive effect on utility because agents enjoy more leisure in expected value. For the parameter values in our exercise, the first effect dominates, and higher volatility of labor effort lowers welfare.

\subsection{The Welfare Ranking}

Table 5 reports the estimates of $\sigma_{\mathrm{C}}, \sigma_{\mathrm{L}}$, and $\sigma_{\mathrm{C}, \mathrm{L}}$ under the rules we consider, along with the implied value of the exponent in (35), for the benchmark parameterization. The following welfare ranking emerges, where $\succ$ denotes "preferred to":

$$
D O L \succ T A Y L O R \succ C B=S I T \succ F I T^{\alpha=10} \succ F I T^{\alpha=5} .
$$

Dollarization is preferable to a currency board because of a smaller volatility of consumption. The Taylor rule does better than both dollarization and a currency board on these grounds, but it generates so much labor effort 
volatility to make dollarization preferable. ${ }^{47} \mathrm{~A}$ more aggressive reaction to inflation-what we call flexible inflation targeting-generates a welfare loss by causing consumption to comove positively with leisure. Among alternative inflation targeting regimes, the more aggressive the reaction to inflation, the higher welfare, as increased aggressiveness yields more stable paths for consumption and the labor effort and a smaller negative covariance.

For a better understanding of this welfare ranking, Table 6 displays the standard deviations of some key endogenous variables. Moving from a currency board to dollarization causes the country premium to become somewhat more volatile because there is no longer a (small) dampening effect of yesterday's currency premium on today's country risk. Notwithstanding a more volatile country premium, complete removal of the volatility originating from the currency premium stabilizes the domestic real interest rate, which in turn yields a less volatile consumption.

The standard Taylor rule produces the highest volatility of CPI inflation among the rules we consider. Consistent with the model's implications, this translates into more volatile relative prices, markup, and employment. At the same time, though, the Taylor rule delivers smaller standard deviations of the risk premia, the real interest rate, and hence consumption. Raising the coefficient on inflation in the Taylor rule to 5 is not sufficient to stabilize the markup and ends up causing substantially more volatile premia. The rule performs better with a coefficient on inflation equal to 10, which stabilizes inflation and the markup significantly and yields standard deviations for the premia that are closer to those under a currency board. ${ }^{48}$

As we noted when evaluating the ability of the framework to match Argentine data, raising the value of $\chi$ reduces premia and consumption volatility. Therefore, raising $\chi$ may affect the welfare ranking. For $\chi \geq 1$, the welfare

\footnotetext{
${ }^{47} \mathrm{As}$ we shall see, the performance of the Taylor rule turns out to be quite sensitive to the value of $\chi$.

${ }^{48}$ Of course, a Taylor rule in which the reaction to inflation is arbitrarily large will approximate the results under strict inflation targeting and a currency board in our setup. However, we confine our attention to reasonable values of the inflation coefficient.
} 
ranking becomes: ${ }^{49}$

$$
D O L \succ C B=S I T \succ F I T^{\alpha=10} \succ F I T^{\alpha=5} \succ T A Y L O R
$$

Table 7 shows some key moments and welfare results for $\chi=1,10,100$. As $\chi$ increases, the domestic economy holds larger steady-state real balances and reserves $(\overline{r e s}=33.1,41.7$, and 52.5 for $\chi=1,10,100$, respectively). Steady-state levels of other variables are not affected by changes in $\chi$. The size of steady-state reserves matters for the dynamics of domestic (private) net foreign assets through the log-linear version of equation (29). Larger steady-state reserves yield less volatile net foreign assets and risk premia, thereby stabilizing consumption. For instance, if $\chi=100$, the difference between dollarization and a currency board on welfare grounds is very small.

Important implications follow: The central bank's average foreign reserve holdings matter for the business cycle properties of alternative monetary regimes. A sufficiently large stock of reserves allows a currency board to match dollarization on welfare grounds. Finally, if the country were to operate a flexible exchange rate regime, an aggressive reaction to inflation coupled with large average reserve holdings would perform better. (And it would outperform the standard Taylor rule, which becomes absurdly destabilizing for $\chi>1$ in our setup.)

These results provide an important motivation for why emerging market countries may want to hold relatively large stocks of foreign reserves, even exceeding the "currency board coverage." Note, however, that reserve holdings are tied to money demand in our model. This is not a restrictive assumption to the extent that supply of U.S. assets in international capital markets is virtually unlimited. But one could wonder if the results would hold in a model in which the central bank accumulates reserves in excess of its money supply, i.e., a model in which reserves are not money-demand determined and become an explicit policy variable.

To verify this, with particular reference to the implications above, we ran simulations of the model under a currency board regime with $\chi=.001$ and progressively higher steady-state reserves not determined by domestic money demand. The results (not reported) strongly supported our conclusions. For

\footnotetext{
${ }^{49}$ These results are based on the welfare criterion above, which does not include utility from real balances. As $\chi$ rises, it is indeed appropriate to consider the latter explicitly in welfare calculations. When we do that we find that considering utility from real balances does not affect the welfare ranking produced by the consumption-leisure criterion. On the contrary, it reinforces the results (not reported, but available on request).
} 
instance, $\overline{r e s}=240$ generated the following second moments: $\sigma_{\mathrm{C}}=3.21$, $\sigma_{\mathrm{L}}=1.02, \sigma_{\mathrm{C}, \mathrm{L}}=1.4$, implying a value of 91.4 for the exponent in equation (35). As before, this was accomplished through a decrease in the volatility of asset accumulation and risk premia $\left(\sigma_{\mathrm{as}}=6.37, \sigma_{\mathrm{p}^{H}}=5.3, \sigma_{\mathrm{p}^{\$}}=5.75\right)$.

In sum, our exercise suggests that dollarization dominates on welfare grounds if reserves are tied to domestic money demand and the latter is small. But a currency board can match dollarization-and do even better-if the central bank accumulates a sufficiently large stock of foreign reserves in excess of domestic money in circulation.

\section{Conclusions}

We presented a framework for analyzing the choice of monetary regime for an open, developing economy with liberalized capital account. This framework combines a dynamic microfounded model of the business cycle for a small open economy with an empirical model for the dynamics of foreign variables and risk premia affecting the economy in question. We departed from the traditional focus of the literature on the terms of trade as one of the main sources of external shocks buffeting these economies, to focus explicitly on the role of risk premia in asset markets. We distinguished between a country premium, reflecting "transaction costs" on holdings of domestic bonds regardless of currency of denomination, and a currency premium, reflecting additional costs related to the currency denomination of these bonds. In this framework, premia are both a source of exogenous shocks to the home economy and a channel through which the consequences of other foreign and domestic shocks are amplified.

Comparison of the second moments implied by a reasonable calibration of the framework to those obtained from actual data for the currency board period in Argentina shows that the framework matches key features of the data remarkably well, especially for those variables that enter welfare calculations directly.

Our framework makes it possible to differentiate a currency board and dollarization explicitly. In our setup, dollarization removes the currency premium. It does not affect the long-run level of the country premium. Instead, it affects the short-run dynamics of the latter to an extent captured by the estimated effect of the currency premium on the country premium under a currency board. Arbitrage and exogeneity of foreign variables imply that 
dollarizing does not alter the steady-state position of real domestic variables. The business cycle and welfare properties of a currency board are equivalent to those of a strict inflation targeting regime in our framework, as foreign inflation is assumed constant based on empirical evidence, and PPP holds.

Welfare analysis of alternative monetary regimes for our baseline parameterization suggests that dollarization is the best among the rules we consider. Dollarization is preferable to a currency board because it removes the volatility originating from the currency premium. Both dollarization and a currency board yield higher welfare levels than variants of the Taylor rule (flexible inflation targeting regimes) in which the central bank reacts more aggressively to inflation than usually assumed.

The standard Taylor rule is the second-best in the set of regimes we consider, ranking higher than a currency board. But if the domestic economy holds larger steady-state money balances and foreign reserves than in the baseline exercise, the standard Taylor rule performs very poorly. In this case, dollarization and a currency board dominate all versions of the Taylor rule we consider. Among these rules, those that place a large coefficient on inflation do better.

Interestingly, the central bank's steady-state stock of foreign reserves affects the business cycle properties of a currency board. If the central bank holds a sufficiently large average stock of reserves (possibly in excess of domestic money supply), a currency board matches dollarization on welfare grounds and can even do better. This result helps explain demand for reserves in emerging market economies.

\section{A The Balance of Payments in a Non-Dollarized Economy}

The home government's period budget constraint in aggregate per capita terms can be written as:

$$
\begin{aligned}
& (1+n)\left(B_{t+1}+B_{t+1}^{C B}+\varepsilon_{t} B_{t+1}^{\$}+\varepsilon_{t} B_{t+1}^{\$ C B}\right) \\
= & p_{t}^{\$}\left(1+i_{t}^{H}\right)\left(B_{t}+B_{t}^{C B}\right)+\varepsilon_{t}\left(1+i_{t}^{\$}\right)\left(B_{t}^{\$}+B_{t}^{\$ C B}\right)+ \\
& P_{t}\left(G_{t}-T_{t}\right)-p_{t}^{\$} i_{t}^{H} B_{t}^{C B}-\varepsilon_{t} i_{t}^{\$} B_{t}^{\$ C B}-\varepsilon_{t} i_{t}^{*} R E S_{t}
\end{aligned}
$$

where $B_{t+1}\left(B_{t+1}^{\$}\right)$ is the stock of home currency (dollar) denominated government bonds held by private agents at the end of period $t, B_{t+1}^{C B}\left(B_{t+1}^{\$ C B}\right)$ 
are bonds held by the central bank. The interest payments on the central bank's holdings of government bonds and foreign assets $(R E S)$ are transferred to the government. Government bonds pay the same return as the private sector's, subject to the same premia.

The central bank's period budget constraint in aggregate per capita terms is:

$$
\begin{aligned}
& (1+n)\left(B_{t+1}^{C B}+\varepsilon_{t} B_{t+1}^{\$ C B}+\varepsilon_{t} R E S_{t+1}\right)-M_{t}^{S} \\
= & p_{t}^{\$}\left(1+i_{t}^{H}\right) B_{t}^{C B}+\varepsilon_{t}\left(1+i_{t}^{\$}\right) B_{t}^{\$ C B}+\varepsilon_{t}\left(1+i_{t}^{*}\right) R E S_{t} \\
- & p_{t}^{\$} i_{t}^{H} B_{t}^{C B}-\varepsilon_{t} i_{t}^{\$} B_{t}^{\$ C B}-\varepsilon_{t} i_{t}^{*} R E S_{t}-\frac{M_{t-1}^{S}}{1+n} .
\end{aligned}
$$

The central bank holds bonds issued by the government and foreign assets. Interest income is transferred to the government. Money supply is backed by the bank's assets and obeys:

$$
\begin{aligned}
M_{t}^{S}-\frac{M_{t-1}^{S}}{1+n}= & (1+n) B_{t+1}^{C B}-p_{t}^{\$} B_{t}^{C B}+\varepsilon_{t}\left[(1+n) B_{t+1}^{\$ C B}-B_{t}^{\$ C B}\right] \\
& +\varepsilon_{t}\left[(1+n) R E S_{t+1}-R E S_{t}\right] .
\end{aligned}
$$

If money supply is backed only by holdings of foreign bonds (the case on which we focus in the text), this equation reduces to:

$$
M_{t}^{S}-\frac{M_{t-1}^{S}}{1+n}=\varepsilon_{t}\left[(1+n) R E S_{t+1}-R E S_{t}\right] .
$$

Letting $Q_{t}$ denote aggregate per capita domestic currency denominated assets held by private agents in the home economy (bonds and shares), the household's aggregate per capita budget constraint for all periods after an unexpected shock can be written as: $:^{50} 51$

$$
(1+n)\left(Q_{t+1}+\varepsilon_{t} A_{t+1}^{\$}\right)
$$

\footnotetext{
${ }^{50}$ When aggregating asset holdings across generations, it is important to recall that newborn households have no financial assets.

${ }^{51}$ The arbitrage condition between bonds and shares between time $t_{0}-1$ and $t_{0}$ has been used to write equation (39). At time $t_{0}$, in which an unexpected shock happens, this arbitrage condition is violated, and equation (39) must be replaced by:
}

$$
\begin{array}{r}
(1+n)\left(Q_{t_{0}+1}+\varepsilon_{t_{0}} A_{t_{0}+1}^{\$}\right) \\
=p_{t_{0}}^{\$}\left(1+i_{t_{0}}^{H}\right) A_{t_{0}}+\varepsilon_{t_{0}}\left(1+i_{t_{0}}^{\$}\right) A_{t_{0}}^{\$}
\end{array}
$$




$$
\begin{aligned}
= & p_{t}^{\$}\left(1+i_{t}^{H}\right) Q_{t}+\varepsilon_{t}\left(1+i_{t}^{\$}\right) A_{t}^{\$} \\
& -M_{t}+\frac{M_{t-1}}{1+n}-\varepsilon_{t} M_{t}^{\$}+\frac{\varepsilon_{t} M_{t-1}^{\$}}{1+n}+W_{t} L_{t}-P_{t} C_{t}-P_{t} T_{t} .
\end{aligned}
$$

Total domestic currency and dollar denominated assets held by households, include bonds issued by the government: $Q_{t}=B_{t}+P B_{t}+V_{t-1}, A_{t}^{\$}=$ $B_{t}^{\$}+P B_{t}^{\$}$. $V_{t-1}$ is the aggregate per capita value of shares in home firms entering period $t$. $P B\left(P B^{\$}\right)$ denotes home households net holdings (relative to foreign agents') of domestic currency (dollar denominated) bonds not issued by the government ${ }^{52}$.

Shares are a liability in the firms' balance sheets. When arbitrage conditions are satisfied, the aggregate per capita equity value of the home economy entering period $t+1$ must evolve according to

$$
V_{t}=\frac{1+n}{p_{t+1}^{\$}\left(1+i_{t+1}^{H}\right)} V_{t+1}+\frac{D_{t+1}}{p_{t+1}^{\$}\left(1+i_{t+1}^{H}\right)}
$$

where $V_{t} \equiv \frac{a V_{t}^{i}}{N_{t+1}} . \quad D_{t} \equiv \frac{a D_{t}^{i}}{N_{t}}$ denotes aggregate per capita dividends: $D_{t}=$ $P_{t} Y_{t}-W_{t} L_{t}-P_{t} \frac{\phi}{2}\left(\pi_{t}^{P P I}-\bar{\pi}\right)^{2} Y_{t}$.

Equating money demand to money supply in all periods and combining constraints (36), (38), (39), and (40) yields: ${ }^{53}$

$$
\begin{aligned}
& P_{t} Y_{t}+p_{t}^{\$} i_{t}^{H} P B_{t}+\varepsilon_{t} i_{t}^{\$} P B_{t}^{\$}+\varepsilon_{t} i_{t}^{*} R E S_{t} \\
& -P_{t} C_{t}-P_{t} G_{t}-P_{t} \frac{\phi}{2}\left(\pi_{t}^{P P I}-\bar{\pi}\right)^{2} Y_{t} \\
= & (1+n)\left(P B_{t+1}+\varepsilon_{t} P B_{t+1}^{\$}\right)-p_{t}^{\$} P B_{t}-\varepsilon_{t} P B_{t}^{\$} \\
& +\varepsilon_{t}\left[(1+n) R E S_{t+1}-R E S_{t}\right] .
\end{aligned}
$$

Equation (41) is the home country's fundamental budget constraint: the left-hand side (first and second row) is the current account balance, or the

$$
+\frac{a D_{t_{0}}^{i}+a V_{t_{0}}^{i}}{N_{t_{0}}}-M_{t_{0}}+\frac{M_{t_{0}-1}}{1+n}+W_{t_{0}} L_{t_{0}}-P_{t_{0}} C_{t_{0}}-P_{t_{0}} T_{t_{0}} .
$$

Aggregating holdings of shares across home generations alive at each point in time yields 1 because we have assumed that only home agents hold shares in home firms.

${ }^{52}$ To save on notation, we are implicitly assuming that all government debt is held domestically.

${ }^{53}$ We assume that households' real dollar balances are transferred back to the governmnent as part of the lump-sum taxes to which private agents are subject. Hence, holdings of foreign currency do not enter the law of motion for aggregate assets. 
difference between incomes and expenditures; the first part of the righthand side is the capital account (with a minus sign), or the change in home households' holdings of net foreign assets; the third row is the balance of payments, or the change in foreign reserves held by the domestic central bank. ${ }^{54}$ The risk premia affect the current account, by generating oscillations in interest income, and the capital account, by changing the fraction of the principal that is actually repaid in each period.

The home economy's balance of payments equation can be rewritten as the following law of motion for home net foreign assets:

$$
\begin{aligned}
& (1+n)\left(P B_{t+1}+\varepsilon_{t} P B_{t+1}^{\$}\right)+(1+n) \varepsilon_{t} R E S_{t+1} \\
= & p_{t}^{\$}\left(1+i_{t}^{H}\right) P B_{t}+\varepsilon_{t}\left(1+i_{t}^{\$}\right) P B_{t}^{\$}+\varepsilon_{t}\left(1+i_{t}^{*}\right) R E S_{t}+ \\
& P_{t} Y_{t}-P_{t} C_{t}-P_{t} G_{t}-P_{t} \frac{\phi}{2}\left(\pi_{t}^{P P I}-\bar{\pi}\right)^{2} Y_{t} .
\end{aligned}
$$

Dividing both sides by $P_{t}$ and imposing absence of arbitrage opportunities yields:

$$
\begin{aligned}
& (1+n)\left(\frac{P B_{t+1}+\varepsilon_{t} P B_{t+1}^{\$}}{P_{t}}\right)+(1+n) \frac{\varepsilon_{t} R E S_{t+1}}{P_{t}} \\
= & p_{t}^{\$}\left(1+i_{t}^{H}\right) \frac{P_{t-1}}{P_{t}}\left(\frac{P B_{t}+\varepsilon_{t-1} P B_{t}^{\$}}{P_{t-1}}\right)+p_{t}^{\$}\left(1+i_{t}^{H}\right) \frac{P_{t-1}}{P_{t}} \frac{\varepsilon_{t-1} R E S_{t}}{P_{t-1}}+ \\
& Y_{t}-C_{t}-G_{t}-\frac{\phi}{2}\left(\pi_{t}^{P P I}-\bar{\pi}\right)^{2} Y_{t} .
\end{aligned}
$$

Denoting home private sector's real net foreign assets per capita with $a s_{t+1} \equiv \frac{P B_{t+1}+\varepsilon_{t} P B_{t+1}^{\$}}{P_{t}}$, real official reserves per capita with $r e s_{t+1} \equiv \frac{\varepsilon_{t} R E S_{t+1}}{P_{t}}$, and recalling the definition of the real interest rate returns equation (29).

\footnotetext{
${ }^{54}$ If part of the bonds issued by the home government are sold abroad, say $B^{F}$ and $B^{\$ F}$ , the left-hand side of equation (41) must include the term $-\left(p_{t}^{\$} i_{t}^{H} B_{t}^{F}+\varepsilon_{t} i_{t}^{\$} B_{t}^{\$ F}\right)$ to account for payments of interest income abroad. The right-hand side must be adjusted by $-(1+n)\left(B_{t+1}^{F}+\varepsilon_{t} B_{t+1}^{\$ F}\right)+\left(p_{t}^{\$} B_{t}^{F}+\varepsilon_{t} B_{t}^{\$ F}\right)$.
} 


\section{B The Log-Linear Model: A Non-Dollarized Economy}

This appendix presents the log-linear version of the theoretical model. ${ }^{55}$

\section{B.1 Consumption, Labor Supply, Money Demand, and Arbitrage}

Using overbars to denote steady-state levels of variables, private home assets obey the following law of motion in log-linear terms:

$$
\begin{aligned}
\mathrm{as}_{t+1}= & -\frac{\overline{r e s}}{|\overline{a s}|} \mathrm{res}_{t+1}+\frac{\bar{p}^{\$}(1+r)}{1+n} \mathrm{as}_{t}+\frac{\bar{p}^{\$}(1+r)}{1+n} \frac{\overline{r e s}}{|\overline{a s}|} \mathrm{res}_{t}+ \\
& \frac{\bar{p}^{\$}(1+r)\left(\frac{\overline{a s}}{|\overline{a s}|}+\frac{\overline{r e s}}{|\overline{a s}|}\right)}{1+n}\left(\mathrm{p}_{t}^{\$}+\mathrm{i}_{t}^{H}-\pi_{t}^{C P I}\right)+ \\
& \frac{1}{1+n}\left(\frac{\bar{Y}}{|\overline{a s}|} \mathrm{Y}_{t}-\frac{\bar{C}}{|\overline{a s}|} \mathrm{C}_{t}-\frac{\bar{C}}{|\overline{a s}|} \mathrm{G}_{t}\right) .
\end{aligned}
$$

As steady-state asset holdings are negative if the home private sector is a borrower in steady state, $\mathrm{as}_{t}$ is defined as $\frac{a s_{t}-\overline{a s}}{|\overline{a s}|}$. Government spending is normalized by steady-state consumption because the steady-state level of $G$ implied by our parameterization of the model is extremely small.

Reserves are determined by:

$\operatorname{res}_{t+1}=\frac{1+\bar{e}}{(1+\bar{\pi})(1+n)}\left(\operatorname{res}_{t}+\mathrm{e}_{t}-\pi_{t}^{C P I}\right)+\frac{\bar{m}}{(1+n) \overline{r e s}}\left(\mathrm{~m}_{t}-\frac{\mathrm{m}_{t-1}-\pi_{t}^{C P I}}{1+\bar{\pi}}\right)$.

Consumer assets are:

$$
\operatorname{asc}_{t}=\frac{|\overline{a s}|}{|\overline{a s c}|} \mathrm{as}_{t}+\frac{\bar{v}}{|\overline{a s c}|} \mathrm{v}_{t-1}
$$

where we allow for the possibility that households' assets be negative in steady state.

\footnotetext{
${ }^{55}$ Recall that all sans serif variables and inflation rates measure percentage deviations from steady-state levels. Gross rates are used to calculate percentage deviations from the steady state of depreciation, inflation, and interest rates.
} 
The equity value of the home economy is given by:

$$
\mathrm{v}_{t}=-\mathrm{p}_{t+1}^{\$}-\mathrm{i}_{t+1}^{H}+\pi_{t+1}^{C P I}+\frac{1+n}{\bar{p}^{\$}(1+r)} \mathrm{v}_{t+1}+\frac{\bar{d}}{\bar{p}^{\$}(1+r) \bar{v}} \mathrm{~d}_{t+1} .
$$

Dividends are:

$$
\mathrm{d}_{t}=\frac{\bar{Y}}{\bar{d}} \mathrm{Y}_{t}-\frac{\bar{w} \bar{L}}{\bar{d}}\left(\mathrm{w}_{t}+\mathrm{L}_{t}\right) .
$$

Using the Euler equation for consumption and the budget constraint for the representative consumer in each generation it is possible to derive an aggregate consumption function that relates consumption decisions to consumer assets and the present discounted value of the real wage stream between today and the infinite future. In equilibrium: ${ }^{56}$

$$
\begin{aligned}
\mathrm{C}_{t}= & -\Theta_{t}+\frac{\bar{p}^{\$}(1+r) \overline{a s c}\left(\mathrm{p}_{t}^{\$}+\mathrm{i}_{t}^{H}-\pi_{t}^{C P I}\right)}{\bar{p}^{\$}(1+r) \overline{a s c}+\frac{\bar{p}^{\$}(1+r) \bar{w}}{\bar{p}^{\$}(1+r)-1}} \\
& +\frac{\bar{p}^{\$}(1+r)|\overline{a s c}| \mathrm{asc}_{t}}{\bar{p}^{\$}(1+r) \overline{a s c}+\frac{\bar{p}^{\$}(1+r) \bar{w}}{\bar{p}^{\S}(1+r)-1}}+\frac{\frac{\bar{p}^{\$}(1+r) \bar{w}}{\bar{p}^{\$}(1+r)-1} \text { inc }_{t}}{\bar{p}^{\$}(1+r) \overline{a s c}+\frac{\bar{p}^{\$}(1+r) \bar{w}}{\bar{p}^{\S}(1+r)-1}} .
\end{aligned}
$$

inc is the present discounted value of the real wage stream:

$$
\text { inc } \equiv \sum_{s=t}^{+\infty} \widetilde{R}_{t, s} w_{s}
$$

It is possible to verify that the following log-linear equation holds:

$$
\text { inc }_{t}=\frac{1}{\bar{p}^{\$}(1+r)}\left(\text { inc }_{t+1}-\mathrm{p}_{t+1}^{\$}-\mathrm{i}_{t+1}^{H}+\pi_{t+1}^{C P I}\right)+\frac{\bar{p}^{\$}(1+r)-1}{\bar{p}^{\$}(1+r)} \mathrm{w}_{t} .
$$

$\Theta^{-1}$ is the consumption to wealth ratio, where:

$$
\Theta_{t} \equiv \sum_{s=t}^{+\infty} \beta^{\sigma(s-t)}\left(\widetilde{R}_{t, s}\right)^{1-\sigma}\left(\frac{w_{s}}{w_{t}}\right)^{(1-\rho)(1-\sigma)} .
$$

In log-linear terms:

$$
\Theta_{t}=\beta^{\sigma}\left[\bar{p}^{\$}(1+r)\right]^{\sigma-1}\left[\begin{array}{c}
\Theta_{t+1}-(1-\sigma)\left(\mathrm{p}_{t+1}^{\$}+\mathrm{i}_{t+1}^{H}-\pi_{t+1}^{C P I}\right) \\
+(1-\rho)(1-\sigma)\left(\mathrm{w}_{t+1}-\mathrm{w}_{t}\right)
\end{array}\right]
$$

\footnotetext{
${ }^{56}$ See Ghironi (2000) for an example in a simpler framework.
} 
The intratemporal allocation of resources between labor and leisure is governed by the tradeoff equation:

$$
\mathrm{L}_{t}=\frac{1-\rho}{\rho} \frac{\bar{C}}{\bar{w} \bar{L}}\left(\mathrm{w}_{t}-\mathrm{C}_{t}\right) .
$$

Money is endogenous in the model. Monetary policy is conducted by setting the domestic interest rate $\mathrm{i}^{H}$. Domestic real balances are determined by:

$$
\mathrm{m}_{t}=\mathrm{C}_{t}-\frac{\sigma}{\bar{p}^{\$}\left(1+\bar{i}^{H}\right)-1}\left(\mathrm{p}_{t+1}^{\$}+\mathrm{i}_{t+1}^{H}\right)-(1-\rho)(1-\sigma) \mathrm{w}_{t} .
$$

The equation for the growth rate of nominal money balances is helpful to define monetary rules that implement a currency board and inflation targeting. Growth in demand of domestic currency obeys:

$$
\begin{aligned}
\mathrm{g}_{t}^{M}= & \pi_{t}^{C P I}+\mathrm{C}_{t}-\mathrm{C}_{t-1}-\frac{\sigma}{\bar{p}^{\$}\left(1+\bar{i}^{H}\right)-1}\left(\mathrm{p}_{t+1}^{\$}+\mathrm{i}_{t+1}^{H}-\mathrm{p}_{t}^{\$}-\mathrm{i}_{t}^{H}\right) \\
& -(1-\rho)(1-\sigma)\left(\mathrm{w}_{t}-\mathrm{w}_{t-1}\right) .
\end{aligned}
$$

Growth in demand of dollars is:

$$
\begin{aligned}
\mathrm{g}_{t}^{\$}= & -\mathrm{e}_{t}+\pi_{t}^{C P I}+\mathrm{C}_{t}-\mathrm{C}_{t-1}-\frac{\sigma}{\bar{i}^{\$}}\left(\mathrm{i}_{t+1}^{\$}-\mathrm{i}_{t}^{\$}\right) \\
& -(1-\rho)(1-\sigma)\left(\mathrm{w}_{t}-\mathrm{w}_{t-1}\right)
\end{aligned}
$$

where e is the rate of depreciation of the domestic currency:

$$
\mathrm{e}_{t}=\varepsilon_{t}-\varepsilon_{t-1}
$$

and $\varepsilon$ is now the percentage deviation of the exchange rate from its steadystate level.

Domestic and foreign interest rates are related by the arbitrage conditions:

$$
\begin{gathered}
\mathrm{i}_{t}^{H}=\mathrm{i}_{t}^{\$}+\mathrm{e}_{t}-\mathrm{p}_{t}^{\$}, \\
\mathrm{i}_{t}^{\$}=\mathrm{i}_{t}^{*}-\mathrm{p}_{t}^{H} .
\end{gathered}
$$

Purchasing power parity yields:

$$
\pi_{t}^{C P I}=\mathrm{e}_{t}+\pi_{t}^{C P I *}
$$




\section{B.2 Output Supply, Labor Demand, Prices, and Costs}

Domestic production per capita in units of the composite consumption good is:

$$
\mathrm{Y}_{t}=\mathrm{RP}_{t}+\mathrm{L}_{t-\nu}+\mathrm{Z}_{t-\nu}
$$

The relative price $-R P \equiv \frac{p(i)}{P}-$ converts units of differentiated goods into units of the composite consumption basket.

Markup pricing implies that the relative price is:

$$
\mathrm{RP}_{t}=\Psi_{t}+\lambda_{t}
$$

An increase in world demand of the consumption basket causes domestic firms to charge a higher real price. Instead, the time $t$ relative price falls if employment and/or productivity was higher $\nu$ periods ago. By definition of the relative price, it must be $\mathrm{RP}_{t}=\mathrm{RP}_{t-1}+\pi_{t}^{P P I}-\pi_{t}^{C P I} \cdot \mathrm{RP}_{t}$ is a measure of the terms of trade of the domestic economy. ${ }^{57}$

Labor demand at time $t$ is:

$$
\mathrm{L}_{t}=-\omega\left[\sum_{s=t+1}^{t+\nu}\left(\mathrm{p}_{s}^{\$}+\mathrm{i}_{s}^{H}-\pi_{s}^{C P I}\right)+\mathrm{w}_{t}+\Psi_{t+\nu}\right]+\mathrm{Y}_{t+\nu}^{W}+(\omega-1) \mathrm{Z}_{t} .
$$

Output price inflation is a function of CPI inflation, markup dynamics, and the marginal cost to firms of output to be sold $(\lambda)$ :

$$
\pi_{t}^{P P I}=\Psi_{t}-\Psi_{t-1}+\lambda_{t}-\lambda_{t-1}+\pi_{t}^{C P I} .
$$

PPI inflation is faster the faster markup growth, the faster growth in marginal costs, and the faster CPI inflation.

The markup charged by firms at each point in time is:

$$
\Psi_{t}=-\frac{\phi(1+\bar{\pi})^{2}}{\theta-1}\left[\pi_{t}^{P P I}-\frac{1+n}{\bar{p}^{\S}(1+r)} \pi_{t+1}^{P P I}\right] .
$$

Today's markup increases if current PPI inflation is lower: firms accept lower prices but preserve profitability by raising the markup component of prices.

\footnotetext{
${ }^{57}$ Strictly speaking, the terms of trade are $\frac{p(i)}{\varepsilon p^{*}(f)}$, where $p(i)$ is the price of the representative home good, $\varepsilon$ is the exchange rate (in units of domestic currency per dollar), and $p^{*}(f)$ is the price of the representative foreign good. Because the impact of home goods in the world consumption basket is marginal, $\varepsilon p^{*}(f) \simeq \varepsilon P^{*}=P$.
} 
Instead, lower expected PPI inflation tomorrow causes firms to lower the markup, trying to smooth output price dynamics.

The marginal cost of output sold at time $t$ is:

$$
\lambda_{t}=\sum_{s=t-\nu+1}^{t}\left(\mathrm{p}_{s}^{\$}+\mathrm{i}_{s}^{H}-\pi_{s}^{C P I}\right)+\mathrm{w}_{t-\nu}-\mathrm{Z}_{t-\nu} .
$$

\section{Dollarization}

Log-linear equations for the dollarized economy can be easily recovered from those above by proceeding as follows:

- Eliminate the equations for reserve accumulation, demand for domestic real balances, growth in domestic nominal balances, and currency premium.

- Set $\overline{r e s}=\operatorname{res}_{t}=0 \forall t$ in the remaining equations.

- Set $\bar{p}^{\$}=1$ and $\mathrm{p}_{t+1}^{\$}=0 \forall t$ in the remaining equations.

- Eliminate exchange rate depreciation (e), replace $\pi_{t}^{C P I}$ with $\pi_{t}^{C P I *}$, eliminate equation (54).

- Replace $\mathrm{p}_{t}^{\$}+\mathrm{i}_{t}^{H}-\pi_{t}^{C P I}$ with $\mathrm{i}_{t}^{\$}-\pi_{t}^{C P I *}$.

- Recall that producer prices are now set in dollars.

\section{Data}

All variables are in percent deviations from trend, calculated as $\log \left(X_{t} / \bar{X}\right)$, where $X_{t}$ denotes the variable of interest and $\bar{X}$ its trend component.

Gross rates are used to calculate deviations from trend of inflation and interest rates. Inflation rates are calculated as 12-month changes. Argentine net foreign assets are constructed by cumulating the monthly current account balance, which is interpolated from quarterly data.

U.S. variables (output, inflation, the Federal Funds Rate) are detrended by means of an Hodrick-Prescott filter with a smoothing parameter equal to 1600. All Argentine variables are detrended by regressing them on a constant 
and a linear trend. The commodity price index is detrended as the Argentine variables.

Argentine employment and labor force data are interpolated from semiannual series using the RATS procedure INTERPOOL.SRC. Argentine real private and government consumption, GDP, and the current account balance are interpolated from quarterly series by splicing the quarterly figure equally within the period before deseasoning and detrending.

All data are from the International Financial Statistics of the IMF, unless explicitly noted. The Argentine bond spreads are those used by Borensztein and Berg (2000). Employment and labor force data are from the Ministry of the Economy (see Argentine SDDS page on the IMF web site). The value of net foreign assets in 1990 is courtesy of Philip Lane and Gian Maria MilesiFerretti (see Philip Lane's web page: http://econserv2.bess.tcd.ie/plane).

\section{References}

[1] Anthony, M. L., and A. Hughes Hallett (2000), "Should Argentina Adopt the U.S. Dollar?" unpublished manuscript, University of Strathclyde.

[2] Berg, A., and E. Borensztein (2000), "The Pros and Cons of Full Dollarization," IMF WP 00/50.

[3] Calvo, G. A. (1983), "Staggered Contracts in a Utility Maximizing Framework," Journal of Monetary Economics 12:983-998.

[4] Calvo, G. A. (2001), "Capital Markets and the Exchange Rate, with Special Reference to the Dollarization Debate in Latin America," Journal of Money, Credit and Banking 33: 312-334.

[5] Calvo, G. A., and M. Obstfeld (1988), "Optimal Time-Consistent Fiscal Policy with Finite Lifetimes," Econometrica 56: 411-432.

[6] Cooley, T. F., and V. Quadrini (2001): "The Costs of Losing Monetary Independence: The Case of Mexico," Journal of Money, Credit and Banking 33: 370-397.

[7] Devereux, M. B., and P. R. Lane (2000): "Exchange Rates and Monetary Policy in Emerging Market Economies," unpublished manuscript, University of British Columbia and Trinity College. 
[8] Frankel, J. A., and A. K. Rose (2000), "Estimating the Effect of Currency Union on Trade and Output," unpublished manuscript, Harvard University and U.C. Berkeley.

[9] Gali, J., and T. Monacelli (2000): "Optimal Monetary Policy and Exchange Rate Volatility in a Small Open Economy," WP 438, Department of Economics, Boston College.

[10] Gertler, M., S. Gilchrist, and F. M. Natalucci (2000): "External Constraints on Monetary Policy and the Financial Accelerator," unpublished manuscript, New York University and Boston University.

[11] Ghironi, F. (2000), "Macroeconomic Interdependence under Incomplete Markets," Boston College Economics Department WP 471.

[12] Giannini, C. (1992): Topics in Structural VAR Econometrics, 2nd edition, Berlin: Springer.

[13] Goldfajn, I., and G. Olivares (2000), "Is Adopting Full Dollarization the Solution? Looking at the Evidence," PUC-Rio de Janeiro, Department of Economics WP 416.

[14] Hau, H. (2000), "Real Exchange Rate Volatility and Economic Openness: Theory and Evidence," CEPR DP 2356.

[15] Hendry, D. F. (1995), "Dynamic Econometrics," Oxford University Press, Oxford, U.K.

[16] Mendoza, E. (2001), "The Benefits of Dollarization when Stabilization Policy is Not Credible and Financial Markets are Imperfect," Journal of Money, Credit and Banking 33: 440-474.

[17] Mishkin, F. S. (2000), "Inflation Targeting in Emerging Market Countries," NBER WP 7618.

[18] Morón, E., and D. Winkelried (2001): "Monetary Policy Rules for Financially Vulnerable Economies," unpublished manuscript, Universidad del Pacifico and Banco Central de Reserva del Perú.

[19] Neumeyer, P. A., and J. P. Nicolini (2000): "Using Balance Sheet Data to Identify Sovereign Default and Devaluation Risk," unpublished manuscript, Universidad T. di Tella. 
[20] Neumeyer, P. A., and F. Perri (2000), "Business Cycles in Emerging Economies: The Role of Country Risk," unpublished manuscript, Universidad T. di Tella and New York University.

[21] Obstfeld, M. (1998), "Open Economy Macroeconomics: Developments in Theory and Policy," Scandinavian Journal of Economics 100: 247275 .

[22] Oppers, S. E. (2000): "Dual Currency Boards: A Proposal for Currency Stability," IMF WP 00/199.

[23] Parrado, E., and A. Velasco (2001): "Optimal Interest Rate Policy in a Small Open Economy: The Case for a Clean Float," unpublished manuscript, New York University and Harvard University.

[24] Rotemberg, J. (1982), "Monopolistic Price Adjustment and Aggregate Output," Review of Economic Studies 49: 517-531.

[25] Rotemberg, J., and M. Woodford (1997), "An Optimization Based Econometric Framework for the Evaluation of Monetary Policy," in Bernanke, B., and J. Rotemberg (eds.), NBER Macroeconomic Annual: 297-346.

[26] Rotemberg, J., and M. Woodford (1999), "The Cyclical Behavior of Prices and Costs," in Taylor, J. B., and M. Woodford (eds.), "Handbook of Macroeconomics," Amsterdam: North-Holland.

[27] Schmitt-Grohé, S., and M. Uribe (2001), "Stabilization Policy and the Costs of Dollarization," Journal of Money, Credit and Banking 33: 482509 .

[28] Svensson, L. E. O. (2001): "What Is Wrong with Taylor Rules? Using Judgment in Monetary Policy through Targeting Rules," unpublished manuscript, Institute for International Economic Studies, Stockholm University.

[29] Takagi, S., and Y. Yoshida (1999), "Exchange Rate Movements and Tradable Goods Prices in East Asia: An Analysis Based on Japanese Customs Data, 1988-1998," IMF WP 99/31. 
[30] Uhlig, H. (1999), "A Toolkit for Analyzing Nonlinear Dynamic Stochastic Models Easily," in R. Marimon and A. Scott (eds.), Computational Methods for the Study of Dynamic Economies, 30-61, Oxford: Oxford University Press.

[31] Weil, P. (1989), "Overlapping Families of Infinitely-Lived Agents," Journal of Public Economics 38: 183-198. 
Table 1. The Foreign Economy

Dependent Variable YF (Standard Error of Estimate $=0.0034318726$; Adjusted R-squared $=0.48$ ) Variable

1. YF_1 Coeff. Std Er. T-Stat.

2. $\mathrm{YF}_{-} 2$

3. $\mathrm{YF}_{-} 3$

4. IF $-\overline{1}$

5. IF_2

6. IF_3

7. $\mathrm{COMP}$

8. $\mathrm{COMP}_{-} 1$

9. COMP_2

10. COMP_3

11. Constant

12. D9411

13. D9502

14. D9808

15. D9810

\subsection{5}

0.078370385

$-0.136264687$

0.751735932

$-0.449813670$

$-0.153290711$

0.017624359

0.008430070

$-0.032764150$

0.009608543

$-0.000084564$

0.002358478

$-0.002654476$

0.013651799

0.000046622

$\begin{array}{cc}0.129187867 & 5.15268 \\ 0.157649287 & 0.49712 \\ 0.154821718 & -0.88014 \\ 0.391859214 & 1.91838 \\ 0.544167647 & -0.82661 \\ 0.371040211 & -0.41314 \\ 0.024844844 & 0.70938 \\ 0.037344152 & 0.22574 \\ 0.037208600 & -0.88055 \\ 0.024883849 & 0.38614 \\ 0.000438103 & -0.19302 \\ 0.003626613 & 0.65033 \\ 0.003712889 & -0.71494 \\ 0.004030433 & 3.38718 \\ 0.004215621 & 0.01106\end{array}$

Dependent Variable IF (Standard Error of Estimate $=0.0009331695$; Adjusted R-squared $=0.87$ ) Variable

1. $\mathrm{YF}_{-} 1$

2. $\mathrm{YF}_{-} 2$

3. $\mathrm{YF}_{-} 3$

4. IF_1

5. IF_2

6. IF_3

7. COMP

8. $\mathrm{COMP}_{-} 1$

9. COMP_2

10. COMP_3

11. Constant

12. D9411

13. D9502

14. D9808

Coeff.

Std Er.

T-Stat.

0.093720734

$-0.045423992$

$-0.012451523$

0.972877252

$-0.009086113$

$-0.151489112$

$-0.004609234$

0.000615974

0.011994783

$-0.008915304$

0.000044501

0.003637682

0.002850513

0.001403657

$0.035127814 \quad 2.66799$

$0.042866834-1.05965$

$0.042097983-0.29577$

$0.106551475 \quad 9.13058$

0.147966063

0.100890524

$-0.06141$

0.006755627

0.010154347

0.010117489

0.006766233

0.000119126

0.000986122

0.001009581

0.001095926

$-0.003487569$

0.001146281

$-1.50152$

$-0.68228$

0.06066

1.18555

$-1.31762$

0.37356

3.68888

2.82346

1.28080

15. D9810

$-3.04251$ 


\section{Table 1. The Foreign Economy (Continued)}

Diagnostic tests at system level (P-values in squared brackets; * $\left.{ }^{* *}\right)$ means that the null hypothesis is rejected at 5 (10) percent of confidence level)

Vector Normality: $\mathrm{Chi}^{\wedge} 2$ ( 4): 3.181 [0.5280]

Vector Heteroscedasticity (using squares): Chi^2(42), 45.917 [0.3131]

Vector Heteroscedasticity (using squares and cross-products): Chi^2(105), 122.05 [0.1222]

YF equation, error autocorrelation in from lags 1 to 24: $\mathrm{Chi}^{\wedge} 2(24), 22.988$ [0.5205]

IF equation, error autocorrelation in from lags 1 to 24: $\mathrm{Chi}^{\wedge} 2(24), 26.774$ [0.3151]

CovariancelCorrelation Matrix of Reduced Form Residuals

YF

YF 0.000009217369

IF

IF 0.000000092556

0.0369291276

0.000000681500

Covariance Matrix of Structural Form Residuals

\begin{tabular}{ll}
\multicolumn{1}{c}{ YF } & \multicolumn{1}{c}{ IF } \\
YF 0.0000094648 & 0.0000 \\
IF 0.0000 & 0.000006163
\end{tabular}

Matrix of Contemporaneous Effects (Standard error in brackets)

$\begin{array}{cc}\text { YF } & \text { IF } \\ \text { YF } 1.0000 & 0.0000 \\ \text { IF } 0.00034771(0.0314) & 1.0000\end{array}$

Notes: Reduced form estimated by OLS; Structural form estimated by FIML. Sample: 1994:4-1999:12. 
Table 2. The Risk Premia

Dependent Variable P\$ (Standard Error of Estimate $=0.012701135$; Adjusted R-squared $=0.71$ )

$\begin{array}{lccc}\text { Variable } & \text { Coeff. } & \text { Std Er. } & \text { T-Stat. } \\ \text { 1. P\$_1 } & -0.018157289 & 0.178015759 & -0.10200 \\ \text { 2. P\$_2 } & -0.171983229 & 0.163004072 & -1.05509 \\ \text { 3. P\$_3 } & -0.295150495 & 0.158721076 & -1.85955 \\ \text { 4. PH_1 } & 0.542486001 & 0.152348124 & 3.56083 \\ \text { 5. PH_2 } & 0.033482678 & 0.204579123 & 0.16367 \\ \text { 6. PH_3 } & 0.276766123 & 0.174827183 & 1.58308 \\ \text { 7. IF } & -3.161027585 & 2.086866802 & -1.51472 \\ \text { 8. IF_1 } & 1.739567150 & 2.422788533 & 0.71800 \\ \text { 9. IF_2 } & 2.900387108 & 2.133610534 & 1.35938 \\ \text { 10. IF_3 } & -4.389029621 & 1.531269217 & -2.86627 \\ \text { 11. YF } & -0.300658771 & 0.530334054 & -0.56692 \\ \text { 12. YF_1 } & -0.399766742 & 0.671285685 & -0.59552 \\ \text { 13. YF_2 } & -0.773216256 & 0.618101527 & -1.25095 \\ \text { 14. YF_3 } & -0.115735252 & 0.632315373 & -0.18303 \\ \text { 15. NFA } & 0.036393189 & 0.215529564 & 0.16885 \\ \text { 16. NFA_1 } & -0.408208966 & 0.286805892 & -1.42329 \\ \text { 17. NFA_2 } & 0.449900538 & 0.218506252 & 2.05898 \\ \text { 18. NFA_3 } & -0.028520338 & 0.137682692 & -0.20715 \\ \text { 19. Constant } & 0.001336138 & 0.001653780 & 0.80793 \\ \text { 20. D9411 } & -0.017218062 & 0.016649249 & -1.03416 \\ \text { 21. D9502 } & 0.012362648 & 0.018973761 & 0.65157 \\ \text { 22. D9808 } & -0.030247251 & 0.017060008 & -1.77299 \\ \text { 23. D9810 } & 0.003448796 & 0.021452457 & 0.16076\end{array}$

Dependent Variable PH (Standard Error of Estimate: 0.010526915; Adjusted R-squared=0.87)

$\begin{array}{lccc}\text { Variable } & \text { Coeff. } & \text { Std Er. } & \text { T-Stat. } \\ \text { 1. P\$_1 } & -0.085323774 & 0.147542470 & -0.57830 \\ \text { 2. P\$_2 } & 0.015231681 & 0.135100530 & 0.11274 \\ \text { 3. P\$_3 } & -0.143495736 & 0.131550711 & -1.09080 \\ \text { 4. PH_1 } & 0.744777394 & 0.126268700 & 5.89835 \\ \text { 5. PH_2 } & -0.342074473 & 0.169558634 & -2.01744 \\ \text { 6. PH_3 } & 0.436355567 & 0.144899724 & 3.01143 \\ \text { 7. IF } & -1.374787155 & 1.729630475 & -0.79484 \\ \text { 8. IF_1 } & -0.859477373 & 2.008048084 & -0.42802 \\ \text { 9. IF_2 } & 5.274021858 & 1.768372470 & 2.98242 \\ \text { 10. IF_3 } & -4.323240038 & 1.269141807 & -3.40643 \\ \text { 11. YF } & -0.465234127 & 0.439549827 & -1.05843 \\ \text { 12. YF_1 } & -0.035936242 & 0.556372921 & -0.06459 \\ \text { 13. YF_2 } & 0.124436877 & 0.512292992 & 0.24290 \\ \text { 14. YF_3 } & 0.160800852 & 0.524073667 & 0.30683 \\ \text { 15. NFA } & 0.396138600 & 0.178634545 & 2.21759 \\ \text { 16. NFA_1 } & -0.410368935 & 0.237709571 & -1.72635 \\ \text { 17. NFA_2 } & 0.193516102 & 0.181101675 & 1.06855 \\ \text { 18. NFA_3 } & 0.011844301 & 0.114113742 & 0.10379 \\ \text { 19. Constant } & 0.002200840 & 0.001370681 & 1.60565 \\ \text { 20. D9411 } & -0.011224376 & 0.013799179 & -0.81341 \\ \text { 21. D9502 } & -0.068418382 & 0.015725773 & -4.35072 \\ \text { 22. D9808 } & -0.075603095 & 0.014139623 & -5.34690 \\ \text { 23. D9810 } & -0.029644547 & 0.017780159 & -1.66728\end{array}$


Table 2. The Risk Premia (Continued)

Diagnostic tests (P-values in squared brackets; $\left.{ }^{* *}\right)$ means that the null hypothesis is rejected at $5(10)$ percent of confidence level)

Vector normality: $\mathrm{Chi}^{\wedge} 2($ 4), 7.1755 [0.1269]

Vector heteroscedasticity (using squares): $\mathrm{Chi}^{\wedge} 2(54), 67.891$ [0.0969]

Vector heteroscedasticity (using squares and cross-products): Chi^2(162), 177.6 [0.1902]

Error autocorrelation in $\mathrm{P} \$$ equation from lags 1 to 24 : $\mathrm{Chi}^{\wedge} 2(24), 44.152[0.0073]^{* *}$

Error autocorrelation in $\mathrm{PH}$ equation from lags 1 to 24: $\mathrm{Chi}^{\wedge} 2(24), 37.456$ [0.0394]*

CovariancelCorrelation Matrix of Reduced Form Residuals

$\mathrm{P} \$$

P\$ 0.000107545885

PH 0.000045003987
$\mathrm{PH}$

0.5048921279

0.000073877296

Covariance Matrix of Structural Form Residuals (Standard errors in parenthesis)

$\mathrm{P} \$$

$\mathrm{PH}$

$\mathrm{P} \$ 0.000088854$

0.0000

PH 0.0000

0.000057559

Contemporaneous Effects Matrix (Standard errors in parenthesis)

$\mathrm{P} \$$

$\mathrm{P} \$ 1.0000$

PH $-0.266(0.0547)$
$\mathrm{PH}$

$-0.266(0.0547)$

1.0000

Notes: Reduced form estimated by OLS; Structural form estimated by FIML. Sample: 1994:4-1999:12. 
Table 3. Actual and Predicted Second Moments: Volatility and Comovements

\begin{tabular}{|c|c|c|c|c|c|c|c|c|}
\hline & GDP & Foreign GDP & $\begin{array}{c}\text { Foreign Interest } \\
\text { Rate }\end{array}$ & $\begin{array}{l}\text { Currency } \\
\text { Premium }\end{array}$ & $\begin{array}{l}\text { Country } \\
\text { Premium }\end{array}$ & Employment & Consumption & Relative Price \\
\hline \multicolumn{9}{|c|}{ Standard deviation, percent } \\
\hline Argentine data & 3.37 & 0.47 & 0.26 & 2.47 & 2.94 & 1.60 & 4.22 & 2.99 \\
\hline Currency board (Chi $=0.001)$ & 0.29 & 0.41 & 0.43 & 7.88 & 7.45 & 1.03 & 6.02 & 0.35 \\
\hline Currency board $($ Chi $=1)$ & 0.28 & 0.41 & 0.43 & 5.47 & 5.09 & 0.99 & 4.77 & 0.20 \\
\hline \multicolumn{9}{|c|}{ Correlation matrices } \\
\hline \multicolumn{9}{|c|}{ Argentine data } \\
\hline GDP & 1.00 & & & & & & & \\
\hline Foreign GDP & 0.32 & 1.00 & & & & & & \\
\hline Foreign Interest Rate & 0.07 & 0.49 & 1.00 & & & & & \\
\hline Currency Premium & 0.49 & -0.19 & -0.51 & 1.00 & & & & \\
\hline Country Premium & 0.64 & 0.04 & -0.25 & 0.83 & 1.00 & & & \\
\hline Employment & 0.43 & 0.31 & 0.03 & 0.32 & 0.36 & 1.00 & & \\
\hline Consumption & 0.97 & 0.27 & 0.00 & 0.51 & 0.64 & 0.41 & 1.00 & \\
\hline Relative Price & 0.40 & 0.17 & -0.02 & 0.23 & 0.37 & -0.53 & 0.40 & 1.00 \\
\hline \multicolumn{9}{|c|}{ Currency board $($ Chi $=0.001)$} \\
\hline GDP & 1.00 & & & & & & & \\
\hline Foreign GDP & 0.66 & 1.00 & & & & & & \\
\hline Foreign Interest Rate & 0.23 & 0.18 & 1.00 & & & & & \\
\hline Currency Premium & 0.14 & -0.03 & -0.10 & 1.00 & & & & \\
\hline Country Premium & 0.09 & 0.00 & 0.06 & 0.88 & 1.00 & & & \\
\hline Employment & 0.31 & 0.23 & 0.00 & 0.29 & 0.25 & 1.00 & & \\
\hline Consumption & 0.30 & 0.03 & 0.01 & 0.84 & 0.74 & 0.40 & 1.00 & \\
\hline Relative Price & -0.09 & 0.09 & 0.11 & -0.85 & -0.84 & -0.27 & -0.74 & 1.00 \\
\hline \multicolumn{9}{|c|}{ Currency board $($ Chi $=1)$} \\
\hline GDP & 1.00 & & & & & & & \\
\hline Foreign GDP & 0.68 & 1.00 & & & & & & \\
\hline Foreign Interest Rate & 0.23 & 0.17 & 1.00 & & & & & \\
\hline Currency Premium & 0.03 & -0.03 & -0.15 & 1.00 & & & & \\
\hline Country Premium & 0.04 & 0.00 & 0.09 & 0.87 & 1.00 & & & \\
\hline Employment & 0.28 & 0.25 & 0.01 & 0.11 & 0.06 & 1.00 & & \\
\hline Consumption & 0.18 & 0.05 & 0.01 & 0.84 & 0.75 & 0.27 & 1.00 & \\
\hline Relative Price & 0.09 & 0.16 & 0.21 & -0.69 & -0.70 & -0.02 & -0.56 & 1.00 \\
\hline
\end{tabular}

Sample: 1995:3 - 1999:12 
Table 4. Actual and Predicted Second Moments: Serial Correlations with GDP

\begin{tabular}{|c|c|c|c|c|c|c|c|c|}
\hline & GDP & $\begin{array}{c}\text { Foreign } \\
\text { GDP }\end{array}$ & $\begin{array}{c}\text { Foreign } \\
\text { Interest } \\
\text { Rate }\end{array}$ & $\begin{array}{l}\text { Currency } \\
\text { Premium }\end{array}$ & $\begin{array}{l}\text { Country } \\
\text { Premium }\end{array}$ & Employment & Consumption & $\begin{array}{c}\text { Relative } \\
\text { Price }\end{array}$ \\
\hline \multicolumn{9}{|c|}{ Argentine data } \\
\hline$t-5$ & 0.65 & 0.30 & 0.12 & 0.49 & 0.76 & 0.06 & 0.62 & 0.71 \\
\hline $\mathrm{t}-4$ & 0.75 & 0.35 & 0.19 & 0.49 & 0.78 & 0.12 & 0.73 & 0.69 \\
\hline$t-3$ & 0.84 & 0.40 & 0.29 & 0.51 & 0.76 & 0.19 & 0.84 & 0.65 \\
\hline $\mathrm{t}-2$ & 0.90 & 0.44 & 0.36 & 0.51 & 0.73 & 0.26 & 0.89 & 0.59 \\
\hline $\mathrm{t}-1$ & 0.95 & 0.42 & 0.32 & 0.54 & 0.69 & 0.33 & 0.94 & 0.51 \\
\hline $\mathrm{t}$ & 1.00 & 0.33 & 0.07 & 0.50 & 0.65 & 0.43 & 0.98 & 0.41 \\
\hline$t+1$ & 0.93 & 0.46 & 0.19 & 0.50 & 0.67 & 0.61 & 0.92 & 0.20 \\
\hline$t+2$ & 0.88 & 0.39 & 0.17 & 0.49 & 0.61 & 0.64 & 0.86 & 0.08 \\
\hline$t+3$ & 0.82 & 0.33 & 0.15 & 0.45 & 0.54 & 0.66 & 0.81 & -0.05 \\
\hline$t+4$ & 0.73 & 0.23 & 0.14 & 0.43 & 0.47 & 0.67 & 0.72 & -0.16 \\
\hline$t+5$ & 0.64 & 0.15 & 0.07 & 0.37 & 0.39 & 0.69 & 0.62 & -0.25 \\
\hline \multicolumn{9}{|c|}{ Currency Board $($ Chi $=0.001)$} \\
\hline$t-5$ & 0.10 & 0.15 & -0.02 & 0.10 & 0.11 & 0.05 & 0.08 & -0.11 \\
\hline $\mathrm{t}-4$ & 0.16 & 0.25 & -0.01 & 0.11 & 0.14 & 0.08 & 0.09 & -0.13 \\
\hline$t-3$ & 0.25 & 0.38 & 0.01 & 0.13 & 0.16 & 0.12 & 0.12 & -0.14 \\
\hline$t-2$ & 0.39 & 0.60 & 0.04 & 0.15 & 0.18 & 0.17 & 0.14 & -0.15 \\
\hline $\mathrm{t}-1$ & 0.61 & 0.94 & 0.10 & 0.16 & 0.20 & 0.25 & 0.17 & -0.15 \\
\hline $\mathrm{t}$ & 1.00 & 0.66 & 0.23 & 0.14 & 0.09 & 0.31 & 0.30 & -0.09 \\
\hline $\mathrm{t}+1$ & 0.61 & 0.41 & 0.24 & 0.06 & 0.01 & 0.11 & 0.02 & 0.00 \\
\hline$t+2$ & 0.39 & 0.27 & 0.27 & -0.09 & 0.01 & 0.07 & 0.02 & 0.02 \\
\hline$t+3$ & 0.25 & 0.17 & 0.29 & -0.02 & 0.03 & 0.04 & 0.02 & 0.03 \\
\hline$t+4$ & 0.16 & 0.11 & 0.30 & 0.00 & 0.02 & 0.03 & 0.02 & 0.03 \\
\hline$t+5$ & 0.10 & 0.07 & 0.29 & -0.02 & 0.02 & 0.01 & 0.01 & 0.03 \\
\hline \multicolumn{9}{|c|}{ Currency Board $($ Chi $=1)$} \\
\hline$t-5$ & 0.10 & 0.16 & -0.03 & 0.04 & 0.05 & 0.03 & 0.04 & -0.05 \\
\hline$t-4$ & 0.17 & 0.26 & -0.02 & 0.04 & 0.06 & 0.05 & 0.04 & -0.05 \\
\hline$t-3$ & 0.26 & 0.40 & 0.00 & 0.04 & 0.07 & 0.09 & 0.05 & -0.04 \\
\hline $\mathrm{t}-2$ & 0.41 & 0.62 & 0.04 & 0.05 & 0.09 & 0.14 & 0.07 & -0.03 \\
\hline $\mathrm{t}-1$ & 0.63 & 0.97 & 0.10 & 0.06 & 0.10 & 0.22 & 0.10 & 0.00 \\
\hline $\mathrm{t}$ & 1.00 & 0.68 & 0.23 & 0.03 & 0.04 & 0.28 & 0.18 & 0.09 \\
\hline $\mathrm{t}+1$ & 0.63 & 0.43 & 0.25 & 0.00 & 0.01 & 0.09 & 0.02 & 0.14 \\
\hline$t+2$ & 0.41 & 0.28 & 0.28 & -0.07 & 0.02 & 0.05 & 0.01 & 0.15 \\
\hline$t+3$ & 0.26 & 0.18 & 0.30 & -0.03 & 0.03 & 0.02 & 0.01 & 0.14 \\
\hline $\mathrm{t}+4$ & 0.17 & 0.12 & 0.31 & -0.03 & 0.02 & 0.00 & 0.00 & 0.12 \\
\hline$t+5$ & 0.10 & 0.08 & 0.31 & -0.04 & 0.02 & 0.00 & 0.00 & 0.11 \\
\hline
\end{tabular}


Table 5. Welfare Comparison

\begin{tabular}{|c|c|c|c|c|c|}
\hline & $\mathrm{CB} / \mathrm{SIT}$ & DOL & TAYLOR & FIT5 & FIT10 \\
\hline \multicolumn{6}{|c|}{ Standard deviation, percent } \\
\hline Consumption & 6.02 & 4.13 & 3.84 & 7.46 & 6.22 \\
\hline Employment & 1.03 & 1.19 & 14.67 & 13.19 & 4.55 \\
\hline \multicolumn{6}{|c|}{ Covariance } \\
\hline $\begin{array}{l}\text { Consumption and } \\
\text { employment }\end{array}$ & 2.46 & 1.66 & 41.55 & -45.32 & -17.17 \\
\hline \multicolumn{6}{|c|}{ Welfare, exponent } \\
\hline & 343.95 & 158.81 & 258.24 & 1584.46 & 654.27 \\
\hline
\end{tabular}

Table 6. Predicted Volatility

\begin{tabular}{lccccc}
\hline & CB/SIT & DOL & TAYLOR & FIT5 & FIT10 \\
& & & & & \\
GDP & 0.29 & 0.34 & 3.01 & 2.28 & 0.80 \\
Foreign GDP & 0.41 & 0.41 & 0.41 & 0.41 & 0.41 \\
Federal Funds Rate & 0.42 & 0.42 & 0.42 & 0.42 & 0.42 \\
Currency Premium & 7.88 & 0.00 & 3.13 & 11.87 & 8.89 \\
Country Premium & 7.45 & 8.61 & 2.79 & 11.26 & 8.41 \\
Relative Price & 0.35 & 0.29 & 12.31 & 10.92 & 3.66 \\
Real interest rate & 14.88 & 8.59 & 5.46 & 22.60 & 16.85 \\
Net foreign assets & 8.17 & 11.30 & 4.60 & 12.81 & 9.37 \\
Markup & 5.67 & 7.33 & 26.12 & 26.25 & 11.17 \\
CPI inflation & 0.00 & 0.00 & 6.71 & 5.23 & 1.80 \\
Real wage & 6.28 & 4.42 & 11.58 & 8.18 & 5.15 \\
& & & & & \\
\hline
\end{tabular}


Table 7. Higher Values of Chi

\begin{tabular}{|c|c|c|c|c|c|}
\hline & $\mathrm{CB} / \mathrm{SIT}$ & DOL & TAYLOR & FIT5 & FIT10 \\
\hline \multicolumn{6}{|c|}{$C h i=1$} \\
\hline \multicolumn{6}{|c|}{ Standard deviation, percent } \\
\hline Consumption & 4.77 & 4.13 & 8.28 & 4.72 & 4.66 \\
\hline Employment & 0.99 & 1.19 & 42.77 & 6.66 & 3.03 \\
\hline Net foreign assets & 5.77 & 11.30 & 12.12 & 6.46 & 5.95 \\
\hline Country premium & 5.09 & 8.61 & 7.68 & 5.58 & 5.24 \\
\hline Currency premium & 5.47 & 0.00 & 8.22 & 5.92 & 5.59 \\
\hline \multicolumn{6}{|c|}{ Covariance } \\
\hline $\begin{array}{l}\text { Consumption and } \\
\text { employment }\end{array}$ & 1.28 & 1.66 & 241.50 & -16.96 & -8.40 \\
\hline \multicolumn{6}{|c|}{ Welfare, exponent } \\
\hline & 219.65 & 158.81 & 2930.52 & 549.47 & 346.02 \\
\hline \multicolumn{6}{|c|}{$C h i=10$} \\
\hline \multicolumn{6}{|c|}{ Standard deviation, percent } \\
\hline Consumption & 4.43 & 4.13 & 79.60 & 4.21 & 4.29 \\
\hline Employment & 0.99 & 1.19 & 446.90 & 5.51 & 2.67 \\
\hline Net foreign assets & 5.07 & 11.30 & 123.30 & 5.29 & 5.13 \\
\hline Country premium & 4.47 & 8.61 & 79.10 & 4.54 & 4.47 \\
\hline Currency premium & 4.84 & 0.00 & 83.70 & 4.89 & 4.79 \\
\hline \multicolumn{6}{|c|}{ Covariance } \\
\hline $\begin{array}{l}\text { Consumption and } \\
\text { employment }\end{array}$ & 1.03 & 1.66 & 20657.42 & -12.83 & -6.63 \\
\hline \multicolumn{6}{|c|}{ Welfare, exponent } \\
\hline & 191.21 & 158.81 & $375,576.48$ & 416.36 & 285.74 \\
\hline \multicolumn{6}{|c|}{$C h i=100$} \\
\hline \multicolumn{6}{|c|}{ Standard deviation, percent } \\
\hline Consumption & 4.04 & 4.13 & 8.70 & 3.81 & 3.94 \\
\hline Employment & 0.99 & 1.19 & 47.80 & 4.49 & 2.37 \\
\hline Net foreign assets & 4.45 & 11.30 & 13.20 & 4.42 & 4.43 \\
\hline Country premium & 3.83 & 8.61 & 8.40 & 3.69 & 3.80 \\
\hline Currency premium & 4.19 & 0.00 & 8.90 & 4.01 & 4.13 \\
\hline \multicolumn{6}{|c|}{ Covariance } \\
\hline $\begin{array}{l}\text { Consumption and } \\
\text { employment }\end{array}$ & 0.75 & 1.66 & 164.63 & -9.49 & -5.26 \\
\hline \multicolumn{6}{|c|}{ Welfare, exponent } \\
\hline & 160.81 & 158.81 & 5172.77 & 315.48 & 236.11 \\
\hline
\end{tabular}

